\title{
A GELATIN-FILTRATION HEADEND FOR FUEL REPROCESSING SOLUTIONS FROM SILICON- CONTAINING ALUMINUM ALIOYS
}

By

Bill J. Newby

Bernice E. Paige:

Date Written

February 6, 1959

\author{
Chemical Development Section \\ CPP Technical Branch \\ PHIILIPS PETROLEUM COMPANY \\ Atomic Energy Division \\ Idaho Falls, Idaho \\ Contract AT(10-1)-205 \\ IDAHO OPERATIONS OFFICE \\ U. S. Atomic Energy Commission
}




\section{DISCLAIMER}

This report was prepared as an account of work sponsored by an agency of the United States Government. Neither the United States Government nor any agency Thereof, nor any of their employees, makes any warranty, express or implied, or assumes any legal liability or responsibility for the accuracy, completeness, or usefulness of any information, apparatus, product, or process disclosed, or represents that its use would not infringe privately owned rights. Reference herein to any specific commercial product, process, or service by trade name, trademark, manufacturer, or otherwise does not necessarily constitute or imply its endorsement, recommendation, or favoring by the United States Government or any agency thereof. The views and opinions of authors expressed herein do not necessarily state or reflect those of the United States Government or any agency thereof. 


\section{DISCLAIMER}

Portions of this document may be illegible in electronic image products. Images are produced from the best available original document. 


\section{A GELATIN-FILTRATION HEADEND FOR FUEL REPROCESSING SOLUTIONS FROM SILICON- CONTAINING ALUNTNUM ALIOYS}

by

Bila J. Newby

Bernice E. Paige

$\underline{A} \underline{B} \underline{S} \underline{T} \underline{R} \underline{A} \underline{C} \underline{T}$

A laboratory study of a gelatin headend process for feed from siliconcontaining aluminum fuels and plant salvage solutions is described. The optimum conditions for the gelatin treatment of fuel solutions were to boil a 0.1 to $0.5 \mathrm{~N}$ nitric acid solution with 100 milligrams of gelatin per liter for 30 minutes. This treatment improved filtration rates and decreased the surface activity of the filtrate for TBP extraction. A number of possible flowsheets for fuel solutions are presented using gelatin treatment and filtration.

An adequate treatment was not found for salvage solutions of unknown composition because a gelatin dosage which was satisfactory for all solutions could not be selected. The optimum treatment for a salvage solution which was grossly contaminated with zirconium, soluble and colloidal silica, and dibutyl phosphate was to boil a IN acid deficient solution with 600 milligrams of gelatin per liter, $\overline{f i l t e r}$, and use a Hexone extraction system.

A silicic colloid in fuel processing solutions was characterized as a surface active material by this study.

Work done under Contract AT(10-1)-205 to the U. S. Atomic Energy Commission. 
A GELATIN-FILTRATION HEADEND FOR FUEL REPROCESSING SOLUTIONS FROM SILICONCONTAINING ALUMINUM ALIOYS

TABIE OF CONIENTS

I. SUMMARY _. $\ldots \ldots \ldots \ldots$ II

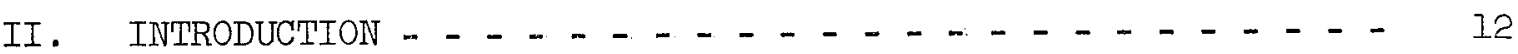

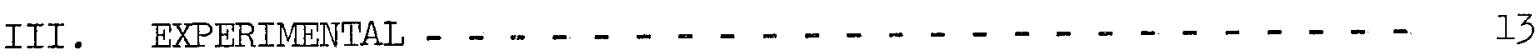

A. Filtration - . . . . . . . . . . . 13

B. Gelatin Treatment - . . . . . . . . . . - 13

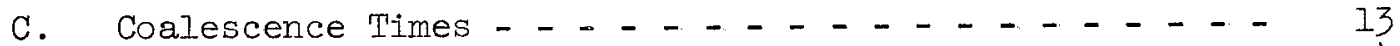

D. Treatment Code- _ . . . . . . . . . - 14

IV. RESULTS _. . . . . . . . . . . . . . - 14

A. Gelatin Treatment of Salvage Solution - - . - - - 14

1. Filtration Conditions- - . - . - . - . - 14

a. Effect of Filter Size and Starting Vacuum - - 15

b. Effect of Gelatin Dosage.. - - . - - - - 18

c. A Six-Hour Filtration Study - - - - - - - 23

2. Gelatin Dosage Requirements of Individual

Constituents - . . . . . . . . . . 23

3. Flowsheet Study of a Grossly Contaminated

Salvage Solution - . . . . . . . . . . 26

B. Gelatin Treatment of Fuel Solutions - . . - . - . 30

1. Hexone Flowsheet Study _. . . . . . . . 30

2. Effect of Acidity on Gelatin Coagulation - . - - 32

3. TBP Flowsheet Study- _ _. . . _ . . . . . 34

4. Effect of Temperature on Gelatin Coagulation - - 36

a. Coagulation Temperature _ . . . . . . . 36

b. Coagulation Time at Constant Temperature- - - 36

c. Effect of Pre-Gelled Gelatin- _ . . . . 36

5. Filter Pore Size - _ . - . - - - . - .. 40

6. Uranium Loss to Filter Cake - . . . . . . . 40

7. Removal of Solids from Filter Pores- - - . - . 44

8. Transfer of Solids from Filters- _ - . - . - 45

C. Characterization of Surface Active Solids _ . . . - . 45

1. Filtration Mechanism and Particle Size

Estimation _. . . . . . . . . . . . 45

2. Possible Identity of the Surface Active Solids - - 47

a. Partition of Solids in the Fuel Solutions - - 47

b. The Consideration of Silica vs. Silicon - - 48

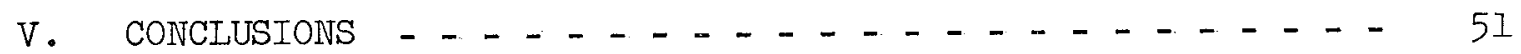

VI. IITERATURE CITED _. . . . . . . . . . . . . 54 
Filtration Data for Salvage Solutions

Filtration Conditions for Solution A - . - . 16

Filtration Conditions for Solution B - - - - - 17

Gelatin Dosage for Solutions A - . - - - - 19

Gelatin Dosage for Solution B - . - . - . - 20

Gelatin Dosage for Solution C - . - . . - 21

Six Hour Filtration Rates for Solutions A and B- - 24

TBP Flowsheet Study of Solution I with Acid

Coggulation - . . . . . . . . - - 27

Hexone Flowsheet Study of Solution I with Acid

Coagulation - . . . . . . . - - - 27

Hexone Flowsheet Study of Solution I with Acid

Deficient Coagulation - . . . . . . - 29

Filtration Data for Fuel Solutions

Hexone Flowsheet Study - - . - . - - - 31

Effect of Acldity on Gelatin Coagulation - . - 33

TBP Flowsheet Study - . - . . - . . . 35

Effect of Temperature on Gelatin Coagulation - - 37

Effect of Coagulation Time at $400 \mathrm{C} \ldots \ldots$

Effect of Using Pre-Gelled Gelatin at Various.

Coagulation Temperatures - . . . . . . 39

Filter Pore Size for $0.5 \mathrm{~N}^{\mathrm{A}}-100-\mathrm{BF}^{\mathrm{A}}$. - . . - . 41

Filter Pore size for $0.5 \bar{N}^{A}-100-B^{B}$ - . . . - 42

Characterization of Surface Active Solids

Filtration Data - Pore Size Study for 0.5NA-O-FA - 46

Microphotograph of Fuel Solution Supernate Before

Gelatin Treatment - . - . . . . - . 49

Microphotograph of Fuel Solution Supernate After

Gelatin Treatment _. . . . . . . . 50

\section{LIST OF TABLES}

Table

Page

$\stackrel{A}{A-1}$

Coalescence Data for Salvage Solutions

Filtration Conditions for Solutions A and B- - - 18

Gelatin Dosage for Solutions A, B, and C - - . - 22

A-2

A-3

A- 4

Effect of Contaminants on Gelatin Dosage - - - - 25

Flowsheet Study of Solution I- - - - - - - 28 


\section{B \\ $\mathrm{B}-1$ \\ $\mathrm{B}-2$ \\ $\mathrm{B}-3$ \\ B -4 \\ $B-5$ \\ $\stackrel{\mathrm{C}}{\mathrm{C}-1}$}

Data for Fuel Solutions

Coalescence Data - Hexone Flowsheet Study - - 32

Coalescence Data - Effect of Acidity on

Gelatin Coagulation - . . . . . . - 34

Coalescence Data - TBP Flowsheet Study - - 34

Uranium Loss Data - Uranium Retention in the

Filter Cake From a Gelatin Headend Treatment 43 Residue Solubility Data - Removal of Solids

from Filter Pores _ - _ . . . . - 45

Characterization of Surface Active Solids

Coalescence Data - Filter Pore Size for

$0.5 \mathrm{~N}^{\mathrm{A}}-\mathrm{O}-\mathrm{F}^{\mathrm{A}} \ldots \ldots . . . \ldots 7$ 


\section{A GEIATIN-FILTRATIOIV HEADEND FOR FUEL REPROCESSING SOLUTIONS FROM SIIICON- CONTAINING ALUMINUM ALLOYS}

By

Bill J. Nvewby

Bernice $\mathrm{E}$. Paige

\section{SUMMARY}

Aluminum-uranium reactor fuels containing silicon may require a headend treatment of the nitric acid dissolver solution prior to uranium recovery by solvent extraction because of the surface active tendencies of these solutions. The laboratory development of a gelatin coagulation and filtration process, which increases the filtration rate and decreases the surface activity associated with the solutions, is described. Flowsheets were considered which would use the batch dissolution and filtration equipment installed at the Idaho Chemical Processing Plant in combination with extraction in either the pulsed columns of the IBP system or the packed columns of the Hexone system. A wide variety of conditions was studied and therefore the data presented should be generally applicable to the chemical processing of silicon-containing aluminum-uranium alloys.

Optimum gelatin treatment for dissolver solutions of aluminumuranium-4 per cent silicon fuels consisted of boiling the 0.1 to $0.5 \mathrm{~N}$ nitric acid solution with $100 \mathrm{mg}$ of gelatin per liter for 30 minutes. The treated solution was readily filterable and the filtrate gave greatly reduced emulsion formation with tributyl phosphate-Amsco compared to untreated feeds. The basic data are given for a number of plant flowsheets.

For gelatin treated solutions, the uranium remaining in the filter cake was reduced from 1.4 to 0.2 per cent of that filtered by use of a 20 volume per cent aluminum nitrate wash. Since the filter cake is readily dispersed in water and completely soluble in caustic, both cleaning of the filter and recovery of the uranium in the cake can easily be accomplished.

The composition of plant sal.vage material, another type of process solution studied, cannot be readily defined because it is a combination of recycle raffinate, off-specifications intermediate product, and salvage from process vessels. Since the actual concentrations of gelatin. consuming components in these solutions was not known, optimum gelatin dosages were established for wide ranges of concentrations of zirconium, soluble silica, colloidal silica, and dibutyl phosphate, in nitric acidaluminum nitrate solutions. It was concluded that solutions of this type would require individual laboratory testing to establish the proper gelatin treatment. 
IDO-14468

Page 12

Interpretation of the experimental results in terms of the nature of the surfactant species led to the conclusion that the silicic surfactant was most probably colloidal, hydrated silica in particles of less than 0.1 micron in apparent diameter, a.lthough the possibility of finely divided silicon as a surfactant was not completely eliminated.

\section{INTRODUCTION}

A high degree of surface activity in aluminum-uranium fuel solutions containing large amounts of silicon has been shown to limit the proper functioning of plant extraction columns. A gelatin treatment combined with a filtration step for solids removal was studied as a possible solution to this problem.

Parrett and Rohde ${ }^{[I]}$ reported low filtration rates for fuel solutions with similar silicon content. Two types of solids were identified. The larger gray solids which settled from solution were identified as crystalline silicon. The other solid, a finely divided brown material, was found to be amorphous by X-ray diffraction. Particle size was also determined. Surface activity was not a problem in these solutions. Known differences from the fuel solutions studied in this report are that they did not contain zirconium or uranium, were higher in acidity, and came from a different metallurgical batch of fuel.

Coagulation of silica in similar solutions with $100 \mathrm{mg}$ of gelatin per liter was reported in DP-293[2]. Gelatin reactions with silica are also described in "The Colloid Chemistry of Silica and Silicates"[3] and "Industrial Chemistry of Colloidal and Amorphous Materials"[4]. The latter text also describes $\mathrm{pH}$ effects and temperature effects upon the gelation of gelatin[5].

Processes for two types of silicon-containing solutions were of particular interest in the work to be described. Because of immediate plant interest, the first phase of this study was the development of a process which could be used to rework salvage solutions which were accumulated during plant operation. These solutions were composites of jetted extraction column interfaces and high uranium raffinates, and were expected to vary greatly in concentrations of silicic, zirconium, and organic contaminants. The second phase of this study was the development of a process for feed from aluminum-uranium fuel which could contain as high as 4 per cent silicon by weight. This report describes the laboratory-scale experiments performed to determine if gelatin headend treatment were applicable to these solutions and if so, what operating conditions were most suitable. Primary interest was in a batch process using ICPP cells where filtration equipment was available. Both the Hexone and TBP extraction flowsheets were considered for the recovery of uranium. From the filtration s.tudies and other selected experiments, information was also obtained as to the nature of the surface active material in these solutions. 


\section{EXPERIMENTAI}

\section{A. $\quad$ Filtration}

Five $250 \mathrm{ml}$ graduated cylinders, which were equipped with rubber stoppers and crucible holders and connected to a vacuum manifold, served as filtrate receivers. The vacuum. was measured with a Bourdon gauge and controlled by a needle valve with an air inlet. Vacuum was applied either at 5 inches of mercury for the first hour and increased to 20 inches of mercury for the second hour, or at 20 inches of mercury throughout the filtration.

Most filtration rate measurements were made using stainless steel filtering crucibles equipped with Teflon O-rings[1] to reduce the filter area to about 0.11 square inch. Later measurements were made using 4 to $8 \mu$ (Ace Glass Company porosity E) sintered glass filtering tubes which were $125 \mathrm{~mm}$ in length and about 0.11 square inch in area. These glass tubes were calibrated with water at 5 inches of mercury vacuum and those selected which had approximately a $1 \mathrm{ml}$ per minute rate. For the sake of speed and convenience, 0.8 square inch sintered glass filters or unrestricted 1.0 square inch stainless steel filters were used when filtration rates were not of interest.

Filtration rate evaluation was based on a comparison to a $16 \mathrm{ml}$ per hour filtration rate when using a 0.11 square inch area filter. This is approximately equivalent to a plant rate of 500 liters through a 4 square foot area filter (plant star filter area) in 6 hours. For comparison purposes, this rate is shown as an " $X$ " mark on all rate curves for 0.11 square inch filters. In some tables a comparison is made of the experimental rate to this $16 \mathrm{~m}$ per hour nate in terms of plus and mirus signs. Due to the inherent difficulties of the Teflon o-ring arrangement only gross differences in filtration rates should be interpreted as significant.

\section{B. Gelatin Treatment}

Gelatin dosage is reported as $\mathrm{mg}$ of gelatin per liter of solution. It was added as a 1 per cent water solution prepared fresh daily from Knox No. I gelatin, USP grade. Gelatin-treated solutions were thoroughly mixed immediately following the gelatin addition.

Unless otherwise specified, gelatin-treated solutions were allowed to coagulate for one hour at $21^{\circ} \mathrm{C}$. In some cases, solutions were boiled with total reflux for 30 minutes or heated in a constant temperature bath during this coagulation period. All filtrations were made at $2 l^{\circ} \mathrm{C}$.

\section{Coalescence Times}

Coalescence times were measured on the single stage pulsed conta
or 6]. The solutions which were tested with 3.25 per cent tributyl phosphate (TBP) in Amsco were left at the final acidity of the treatment steps and ranged from 0.1 to $1.3 \mathrm{~N}$ acid. Solutions tested with Hexone were neutralized with ammonium hydroxide to $0.23 \underline{\mathrm{N}}$ acid deficient ${ }^{\prime}$ or to 
$\mathrm{pH} 2.0$ which is about $\mathrm{IN}$ acid deficient in these solutions. Coalescence times of less than 120 seconds were considered to be excellent and those greater than 300 seconds were consigered to be highly undesirable from the standpoint of column behavior 7 . Insufficient filtrate prevented the measurement of coalescence time in some cases.

\section{Treatment Code}

The treatment coding system used throughout the report relates the history of the sample in the following manner. The first code number $\left(0.5 \mathrm{~N}^{\mathrm{A}}, 0.23 \mathrm{~N}^{\mathrm{B}}\right.$, etc.) indicates the solution identity and the acidity of the solution during the coagulation period. The gelatin concentration as $\mathrm{mg}$ per liter is indicated by the second code number (0,100, etc.). Samples which were boiled during the coagulation are designated by the code letter $B$. "With the exception of the special temperature study, all other samples were coagulated at $21^{\circ} \mathrm{C}$. Solutions were filtered while still acid (code-FA) or neutralized with ammonium hydroxide after coagulation and filtered acia deficient (code- $\mathbb{F}^{B}$ ) for Hexone studies. Samples which were filtered acid $\left(F^{A}\right)$ but coalescence tested with Hexone were neutralized after the filtration step.

\section{RESULTS}

\section{A. Gelatin Treatment of Salvage Solution}

Due to immediate plant interest, the first gelatin headend process studied was for plant salvage solutions. The salvage solutions of interest were composites of jetted column interfaces and high uranium raffinates which had been collected in plant storage tanks for reprocessing. The actual concentrations of components were not known and since these solutions. were highly radioactive, they could not be handled for characterization. Synthetic solutions were made in an effort to simulate these salvage solutions.

Although no process was found which could be used for all salvage solutions, irrespective of composition, certain information gained in this study was carried through to the development of a headend process for fuel solutions.

\section{Filtration Conditions}

The following solutions were used in this study:

Solution A was prepared from a combination of dissolved fuel solutions and contained between 0.3 and 0.6 grams of silicon per liter. The resulting solution was $1.26 \mathrm{~N}^{\mathrm{A}}$, $1.75 \mathrm{M}$ aluminum, 1.31 specific gravity, with $0.001 \mathrm{M}$ uranium and $0.001 \mathrm{M}$ zirconium added. It was saturated with 3 per cent tributȳl phosphate (TBP) in Amsco.

Solution B was grossly contaminated. It was prepared from solution A by adding, $2100 \mathrm{ppm} \mathrm{SiO}_{2}$ as soluble silica (water glass), 


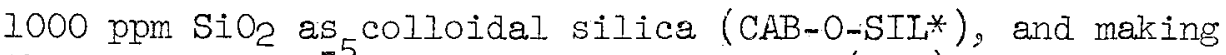
the solution $10^{-5} \mathrm{M}$ in dibutyl phosphate (DBP) and $0.1 \mathrm{M}$ in zirconium.

Solution C was the same as solution B without the scluble silica. It was prepared from solution $\mathrm{A}$ by adding $1000 \mathrm{ppm} \mathrm{SiO}_{2}$ as colloidal silica ( $\mathrm{CAB}-\mathrm{O}-\mathrm{SIL}$ ) and making the solution $10^{-5} \mathrm{M}$ in $\mathrm{DBP}$ and $0 . \mathrm{IM}$ in zirconium.

These experiments were performed to determine the optimum conditions for filtering.

a. Effect of Filter Size and Starting Vacuum. Stainless steel filters equipped with Teflon O-rings were used for these experiments. Filters of 5 and $20 \mu$ porosity were studied since these sizes were readily available in plant filters. The vacuum level studied was either to apply 20 inches of mercury vacuum throughout the filtration or to apply 5 inches of mercury for one hour and then increase to 20 inches of mercury for the remainder of the filtration. The eflect of gelatin addition was also studied in this experiment.

Figures $A-1$ and $A-2$ show the filtration rates obtained for solutions $A$ and $B$, respectively. Table A-l presents the coalescence data obtained from these experiments. It was concluded from these experiments that there was no marked difference in rate or clarity between 5 and $20 \mu$ filters. The larger size might have a slight filtration rate advantage, but the $5 \mu$ filters apparently produced a better quality effluent with regard to coalescence times for borderline cases. Since most of the existing plant filters are $5 \mu$ size, subsequent measurements were made with $5 \mu$ filters. A more complete filter size study is reported in Section B-5 and C-I.

In most cases some advantage in filtration rate was gained by using an initial cake buildup period at 5 inches of mercury vacuum and then increasing the vacuum to 20 inches of mercury to increase the filtration rate. The filtrate quality, as indicated by coalescence time, was improved for solution A, but not for solution B.

The effect of a gelatin treatment was inconclusive in these experiments, but indications were that the dosage requirements were dependent upon the solution composition.

\footnotetext{
*Obtained from Godfrey L. Cabot, Inc., 77 Franklin Street, Boston 10,
} Massachusetts. 
$100-14468$

PAGE 16

FIGURE $A-1$

FILTRATION DATA FOR

SALVAGE SOLUTIONS

FILTRATION CONDITIONS FOR SOLUTION A

-5"-20" OF Hg VACUUM COMBINATION

- - - 20 " OF Hg VACUUM

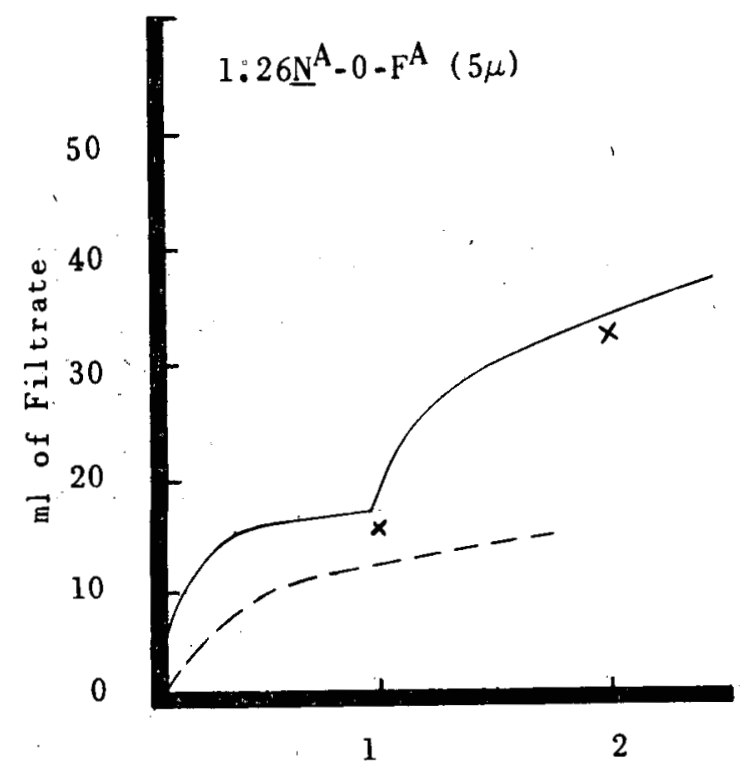

HOURS

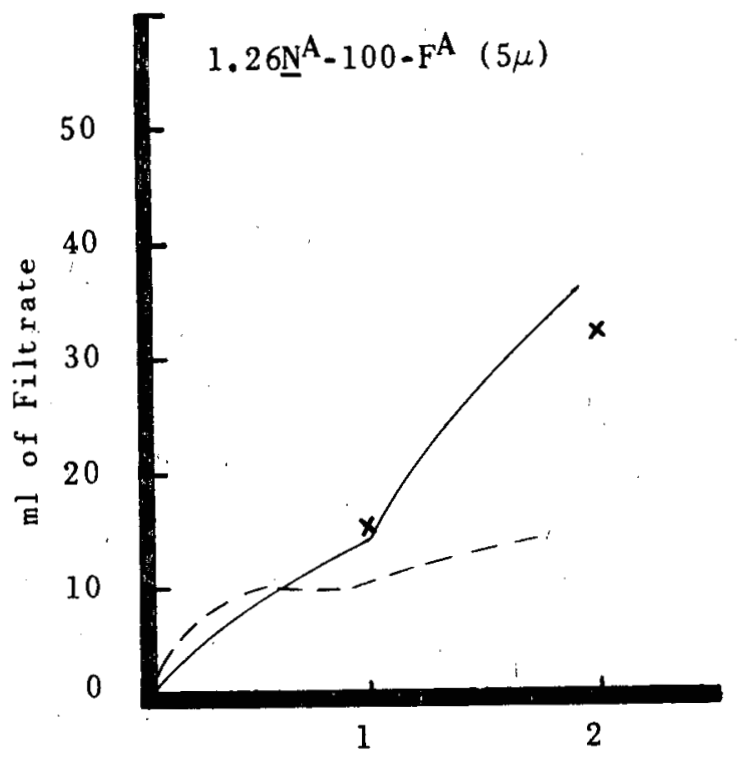

HOURS
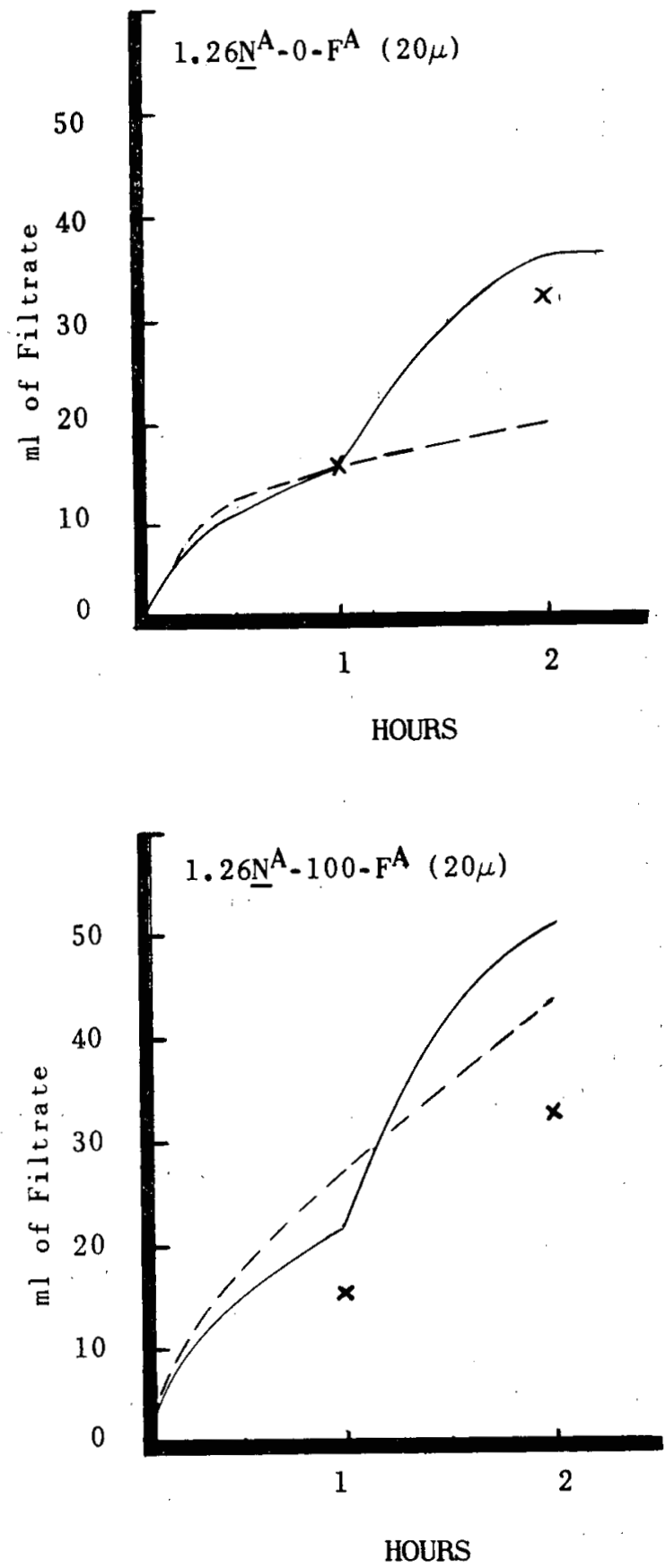

$X=$ REFERENCE FILTER RATE (SEE PAGE 13) 
FIGURE $\quad A-2$

FILTRATION DATA FOR SALVAGE SOLUTIONS

FILTRATION CONDITIONS FOR SOLUTION E

$-5^{\prime \prime}-20^{\prime \prime}$ OF $\mathrm{Hg}$ VACUUM COMBINATION

$---20 "$ OF Hg VACUUM
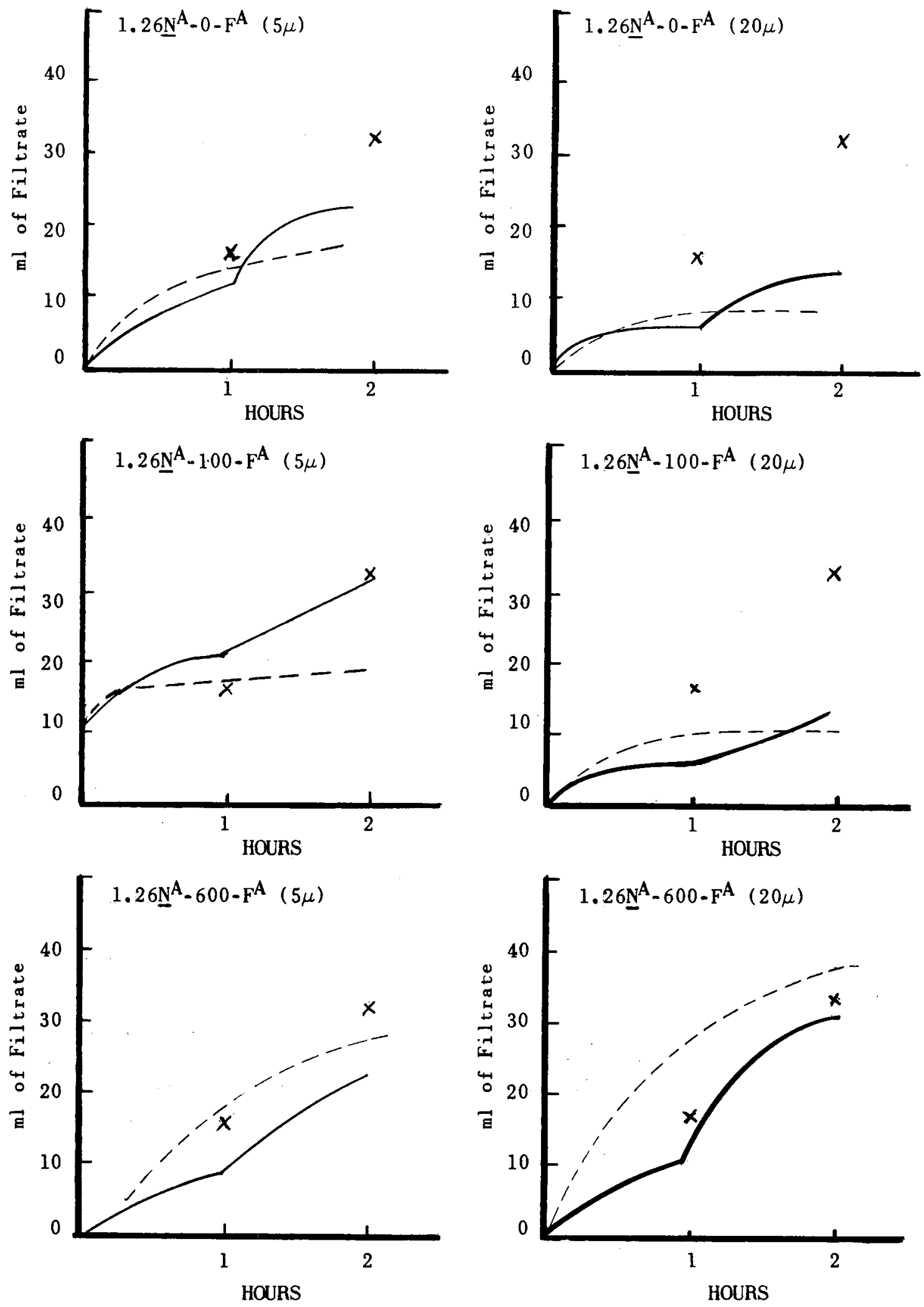
TABLE $A-1$

COATESCENCE DATA FOR SALVAGE SOLUTIONS

FILTRATION CONDITIONS FOR SOLUTIONS A AND B

\begin{tabular}{|c|c|c|c|c|c|}
\hline Solution & $\begin{array}{c}\text { Treatment } \\
\text { Code }\end{array}$ & $\begin{array}{c}\text { Vacuum } \\
\text { Inches } \\
\text { of Mercury }\end{array}$ & $\begin{array}{l}\text { Filter } \\
\text { Size } \\
(\mu) \\
\end{array}$ & $\begin{array}{c}\text { TBP-Amsco } \\
\text { Coalescence } \\
\text { Time(Seconds) }\end{array}$ & $\begin{array}{c}\text { Hexone* } \\
\text { Coalescence } \\
\text { Time (Seconds) }\end{array}$ \\
\hline A & $\begin{array}{l}1.26 \mathrm{~N}^{\mathrm{A}} \mathrm{-}-0-\mathrm{F}^{\mathrm{A}} \\
1.26 \mathrm{~N}^{\mathrm{A}}-0-\mathrm{F}^{\mathrm{A}} \\
1.26 \mathrm{~N}^{\mathrm{A}}-0-\mathrm{F}^{\mathrm{A}} \\
1.26 \mathrm{~N}^{\mathrm{A}}-0-\mathrm{F}^{\mathrm{A}}\end{array}$ & $\begin{array}{c}5-20 \\
20 \\
5-20 \\
20\end{array}$ & $\begin{array}{r}5 \\
5 \\
20 \\
20\end{array}$ & $\begin{array}{r}120 \\
126 \\
420 \\
>600\end{array}$ & $\begin{array}{l}-- \\
-- \\
--\end{array}$ \\
\hline A & $\begin{array}{l}1.26 \mathrm{~N}^{\mathrm{A}}-100-\mathrm{F}^{\mathrm{A}} \\
1.26 \mathrm{~N}^{\mathrm{A}}-100-\mathrm{F}^{\mathrm{A}} \\
1.26 \mathrm{~N}^{\mathrm{A}}-100-\mathrm{F}^{\mathrm{A}} \\
1.26 \mathrm{~N}^{\mathrm{A}}-100-\mathrm{F}^{\mathrm{A}}\end{array}$ & $\begin{array}{l}5-20 \\
20 \\
5-20 \\
20\end{array}$ & $\begin{array}{r}5 \\
5 \\
20 \\
20\end{array}$ & $\begin{array}{r}83 \\
145 \\
75 \\
109\end{array}$ & $\begin{array}{l}105 \\
\overline{66} \\
67\end{array}$ \\
\hline B & $\begin{array}{l}1.26 N^{A}-O-F^{A} \\
1.26 N^{A}-0-F^{A} \\
1.26 \bar{N}^{A}-O-F^{A} \\
1.26 N^{A}-0-F^{A}\end{array}$ & $\begin{array}{l}5-20 \\
20 \\
5-20 \\
20\end{array}$ & $\begin{array}{r}5 \\
5 \\
20 \\
20\end{array}$ & $\begin{array}{r}>600 \\
-- \\
>600 \\
--\end{array}$ & $\begin{array}{l}-- \\
-- \\
--\end{array}$ \\
\hline B & $\begin{array}{l}1.26 N^{A}-100-F^{A} \\
1.26 N^{A}-100-F^{A} \\
1.26 N^{A}-100-F^{A} \\
1.26 N^{A}-100-F^{A}\end{array}$ & $\begin{array}{c}5-20 \\
20 \\
5-20 \\
20\end{array}$ & $\begin{array}{r}5 \\
5 \\
20 \\
20\end{array}$ & $\begin{array}{r}>600 \\
-- \\
>600 \\
--\end{array}$ & $\begin{array}{l}-- \\
-- \\
--\end{array}$ \\
\hline B & $\begin{array}{l}1.26 N^{A}-600-F^{A} \\
1.26 N^{A}-600-F^{A} \\
1.26 N^{A}-600-F^{A} \\
1.26 N^{A}-600-F^{A}\end{array}$ & $\begin{array}{c}5-20 \\
20 \\
5-20 \\
20\end{array}$ & $\begin{array}{r}5 \\
5 \\
20 \\
20\end{array}$ & $\begin{array}{l}110 \\
120 \\
119 \\
106\end{array}$ & $\begin{array}{l}58 \\
55 \\
45 \\
81\end{array}$ \\
\hline
\end{tabular}

* Veutralized to $\mathrm{pH} 2$ with anmonium hydroxide after filtration.

b. Effect of Gelatin Dosage. These experiments were made using $5 \mu$ stainless steel filters with Teflon 0-rings at the 5-20 inches of mercury vacuum combination.

Filtration rate curves for various gelatin dosages are given for solutions $A, B$, and $C$ in Figures A-3, A-4, and A-5, respectively. Five of the filtration rate curves were run in duplicate. 
FIGURE $\quad A-3$

FILTRATION DATA FOR SALVAGE SOLUTIONS

GELATIN DOSAGE FOR SOLUTION A

FILTER SIZE: $5 \mu$ (0.1 sq. in. area)

VACUUMM: $5 "-20^{\prime \prime}$ OF Hg COMBINATION
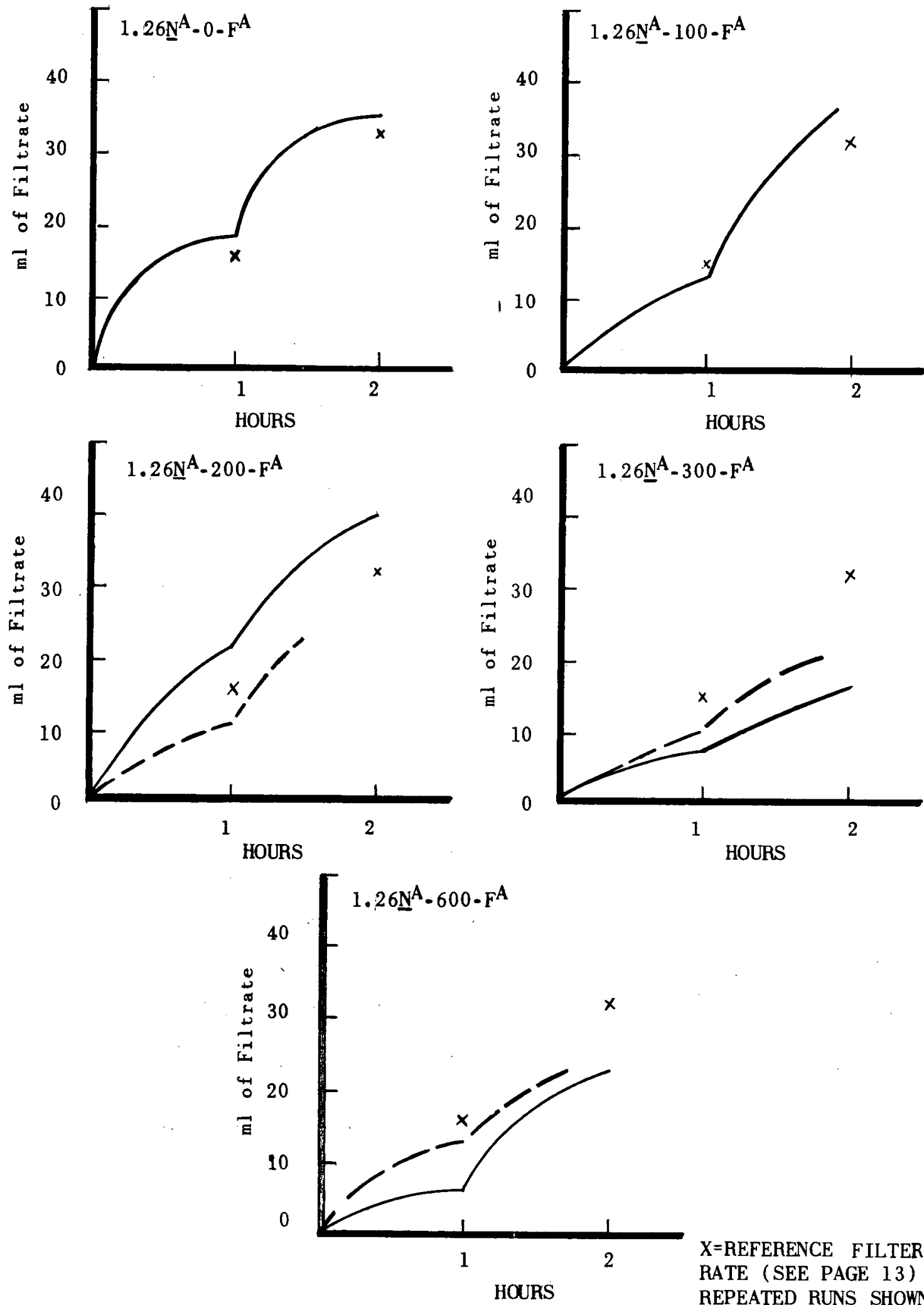

$X=$ REFERENCE FILTER

RATE (SEE PAGE 13) REPEATED RUNS SHOWN BY BROKEN LINE 
PAGE 20

FIGURE $A-4$

FILTRATION DATA FOR SALVAGE SOLUTIONS

GELATIN DOSAGE FOR SOLUTION B

FILTER SIZE: $5 \mu(0.1$ sq. in. area)

VACUUM: $5 "-20 "$ OF $\mathrm{Hg}_{g}$ COMBINATION
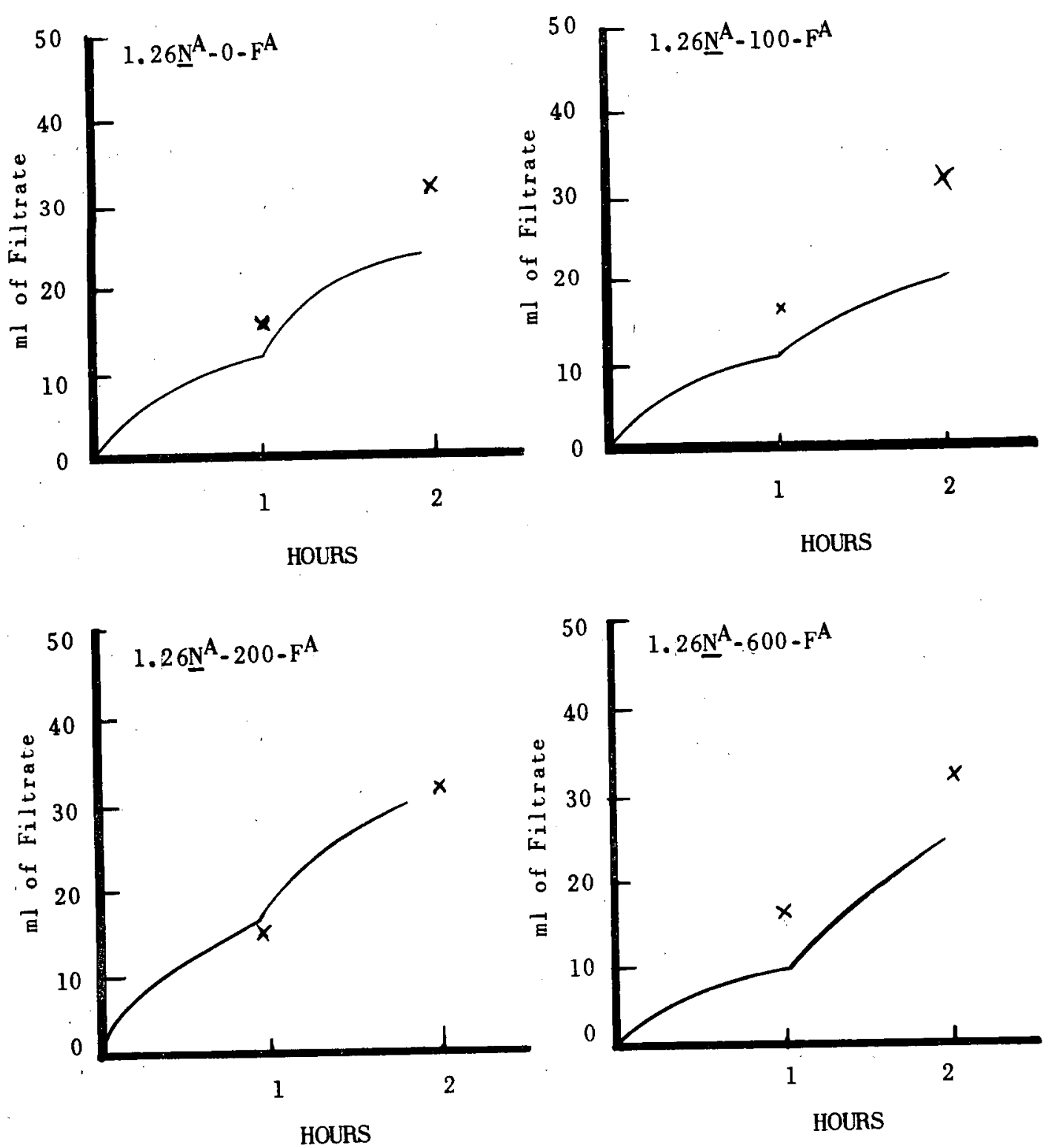


\section{FIGURE A-5}

FILTRATION DATA FCR SALVAGE SOLUTIONS

GELATIN DOSAGE FOR SOLUTION C

FILTER SIZE: $5 \mu(0.1$ sq. in. area)

VACUUM: $5^{\prime \prime}-20^{\prime \prime}$ OF Hg COMBINATION
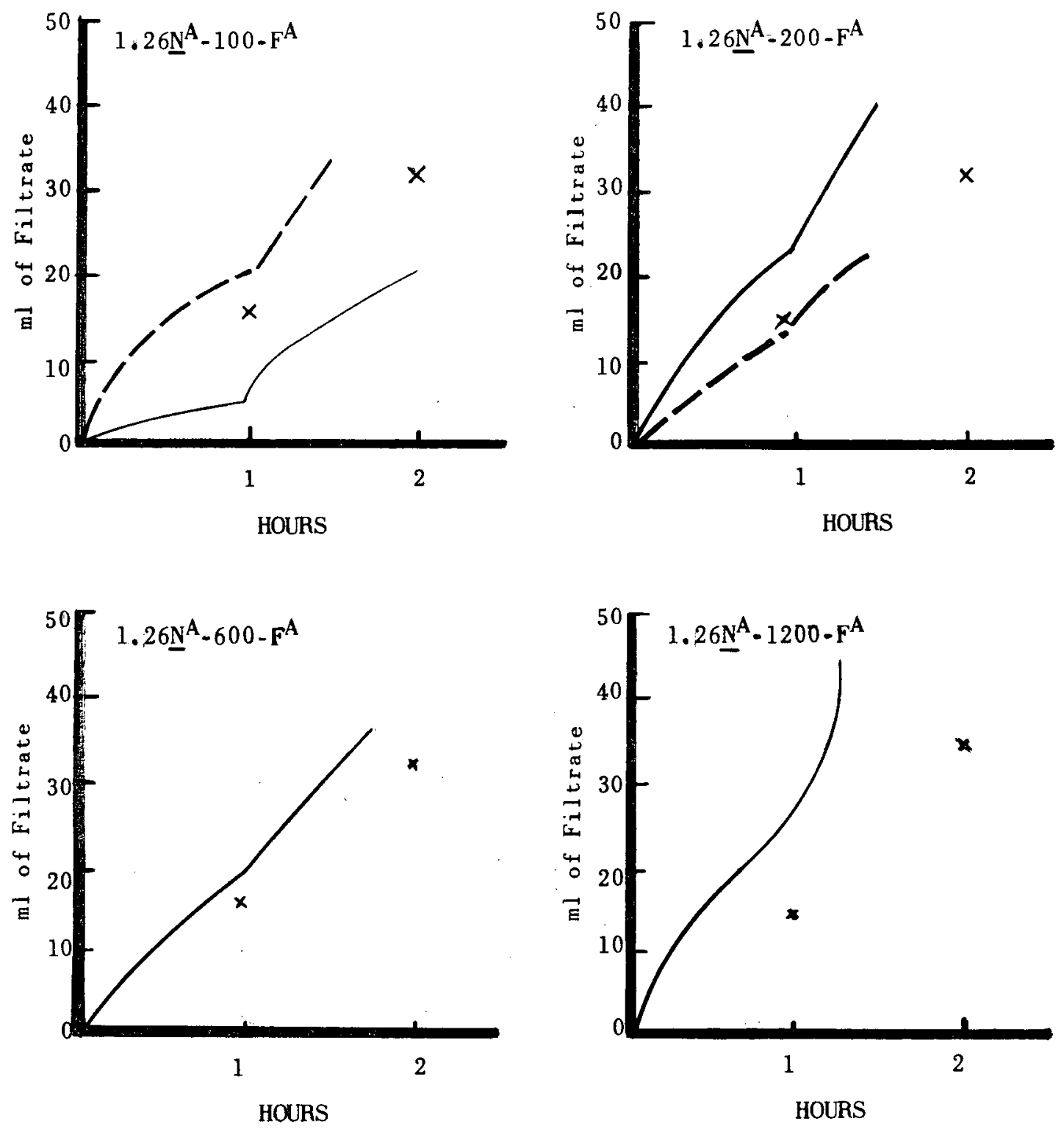

HOURS

$\mathrm{X}=$ REFERENCE FILTER RATE (SEE PAGE 13) REPEATED RUNS SHOWN BY BROKEN LINE 
Based on the filtration rates of the three figures, there is no apparent difference for various gelatin dosages unless it is a slight improvement in solution $\mathrm{C}$ with $1200 \mathrm{mg}$ per liter gelatin. This is to say that differences between duplicates and closely related solutions were as large as the differences from one dosage to the next.

As shown in Table A-2, this was not the case with coalescence times. Although coalescence times were generally good with Hexone, there was considerable variation in the TBP coalescence times. Good results were obtained with a gelatin dosage of $100 \mathrm{mg}$ per liter in solution $A$. Savannah River Plant work 2 reported a similar gelatin dosage as suitable for related solutions. Larger dosages gave erratic results indicating that an overdosage may be detrimental to coalescence times at this acidity.

\section{TABLE A-2}

\section{COAIESCENCE DATA FOR SALVAGE SOLUTIONS}

GELATIN DOSAGE FOR SOLUTIONS A, B, AND C

TBP Hexone*

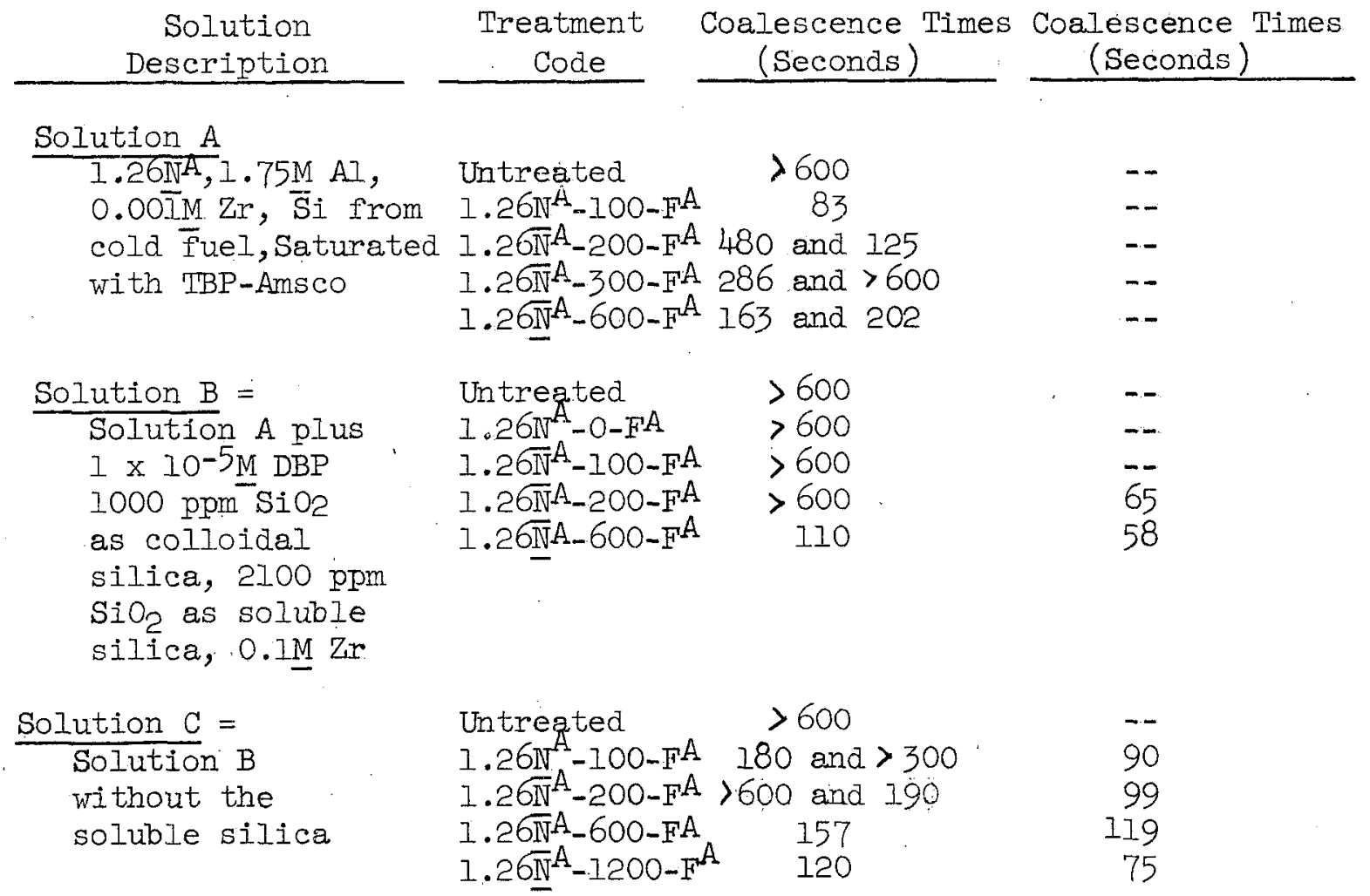

* Neutralized to pH 2 with ammonium hydroxide after filtration.

Both solutions $B$ and $C$ contained grossly exaggerated concentrations of zirconium, dibutyl phosphate, and colloidal gilica (CAB-O-SII). They were alike except that B contained $2100 \mathrm{ppm} \mathrm{SiO}_{2}$ as soluble silica (waterglass). Both solutions had poor or erratic coalescence times at $100 \mathrm{mg}$ per liter gelatin while good results were obtained 
at $600 \mathrm{mg}$ per liter gelatin indicating that soluble silica (waterglass) did not increase the gelatin dosage required in these solutions.

c. A Six-Hour Filtration Study. Filtrations were run for the full 6-hour period using gelatin treatment conditions which appeared to be optimum for each solution. Solutions A and B were studied to determine what effects, such as packing, might occur in a completed plant filtration. Figure A-6 shows the curves obtained for this experiment. Both solution A at $100 \mathrm{mg}$ of gelatin per liter and solution B at $600 \mathrm{mg}$ of gelatin per liter had a faster filtration rate for the $20 \mu$ filters than for the $5 \mu$ filters over a 6 -hour period. The rates obtained for solution $A$ at 100 and $600 \mathrm{mg}$ of gelatin per liter were about the same as were previously obtained for the first hour of filtration; however, they did not show the usual, increase in rate with increase in vacuum and the over-all rate is lower than had been previously obtained. The other rates agree very well with previous 2 -hour runs.

It was concluded that since there is no appreciable change in the filtration rate after the first 2 hours of filtration, 2-hour curves can be extrapolated to a 6 -hour rate of $96 \mathrm{ml}$ : per 6 hours or a proximately a 500 liters per 6 hours plant filtration rate.

\section{Gelatin Dosage Requirements of Individual Constituents}

This experiment was performed to determine the relationship between gelatin dosage and the individual contaminants in salvage solutions. The following solutions were used for this study:

Solution $E$ was prepared from a continuous dissolver effluent of nonirradiated fuel element segments and contained between 0.2 and 0.3 grams of silicon. The solution was $1.28 \mathrm{~N}^{\mathrm{A}}$ and $1.74 \mathrm{M}$ aluminum. It was saturated with TBP and Ams $\bar{c} 0$, and made $0.001 \mathrm{M}$ in uranium and $0.001 \mathrm{M}$ in zirconium. It was similar to solution $A$.

Solution $F$ was prepared by adding $1000 \mathrm{ppm} \mathrm{SiO}_{2}$ as colloidal silica (CAB-O-SIL) to solution $\mathrm{E}$.

Solution G was prepared by adding $1000 \mathrm{ppm} \mathrm{SiO}_{2}$ as soluble, silica (waterglass) to solution $\mathrm{E}$.

Solution H was solution E made O.IM in zirconium.

For these experiments one square inch sintered glass crucibles of 4 to $5 \mu$ porosity (fine) were used with a 5-20 inches of mercury vacuum combination. Filtration rates were not considered of interest since no distinct difference had been found for solutions A, B, and C at various. gelatin dosages.

Table A-3 shows the coalescence times for these experiments. There was a definite maximum dosage which could be tolerated in each solution. The maximum tolerable dosage of gelatin was $100 \mathrm{mg}$ per liter 
FILTRATION DATA FOR SALVAGE SOLUTIONS

6 HOUR FILTRATION RATES FOR SOLUTIONS A AND B

VACUUM: $5^{n-2} \mathrm{O}^{n} \mathrm{Hg}$ COMBINATION
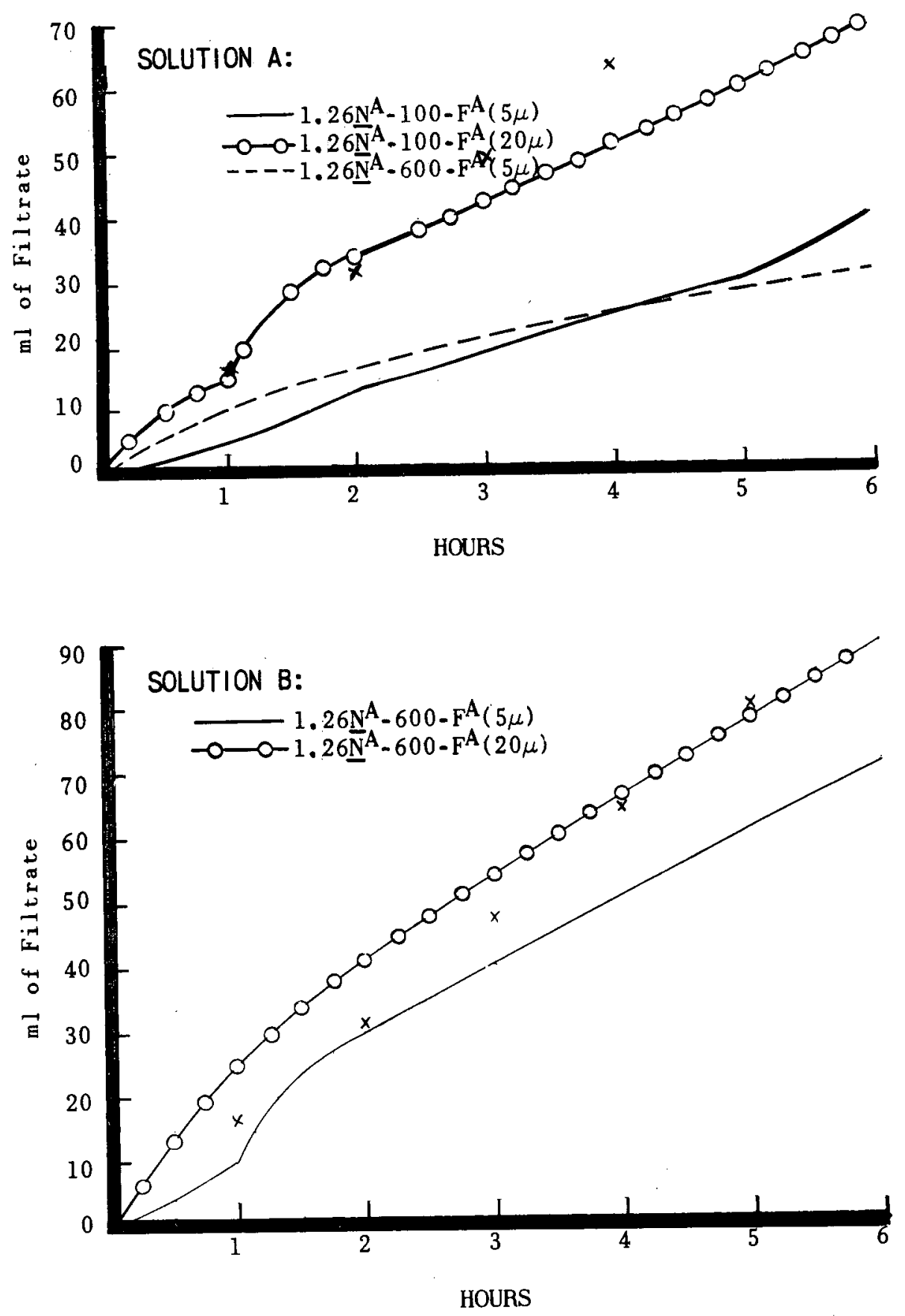
for solutions $E$ and $G$ as it had been for solution $A$. If this dosage was indeed related to the quantity of contaminant material which "reacted" with the gelatin, then it may be concluded that no contaminant was added by adding soluble silica as waterglass. This agrees with the conclusion obtained from solutions $B$ and $C$.

TABIE A-3

COAIESCENCE DATA FOR SALVAGE SOLUTIONS

EFFECT OF CONTAMTNANTS ON GETATIN DOSAGE

Colorimetric

Coalescence Time Analysis of

Solution

Description

Solution E

$1.74 \mathrm{M} \mathrm{A} I, 1.28 \mathrm{~N}^{\mathrm{A}}$,

$0.00 \overline{\mathrm{M}} \mathrm{U}, 0.00 \overline{\mathrm{I}} \mathrm{M} \mathrm{Zr}$,

silicon from cold fuel,

saturated with TBP-

Amsco

Treatment
Code

$1.28 \underline{N}^{\mathrm{A}}-0$

$1.28 \mathrm{~N}^{\mathrm{A}}-100-\mathrm{F}^{\mathrm{A}}$
$1.28 \bar{N}^{\mathrm{A}}-200-\mathrm{F}^{\mathrm{A}}$

$1 \cdot 28 \bar{N}^{A}-200-F^{A}$
$1.28 \bar{N}^{A}-600-F^{A}$ with 3\% TBP-

Amsco (Seconds)

Solution F

Solution E plus 1000

ppm $\mathrm{SiO}_{2}$ as colloidal

silica
Soluble Silica

(mg Si/e)

Solution G

Solution E plus 1000

ppm $\mathrm{SiO}_{2}$ as soluble silica

$$
\begin{aligned}
& 1.28 \mathrm{~N} A-0 \\
& 1.28 \bar{N} A-100-F^{A} \\
& 1.28 \bar{N}^{A} A-200-F^{A} \\
& 1.28 \bar{N} A-600-F^{A} \\
& 1.28 \bar{N}{ }^{A}-1200-F^{A}
\end{aligned}
$$

$$
\begin{array}{lr}
1.28 \mathrm{~N}^{\mathrm{A}}-\mathrm{O} & >600 \\
1.28 \overline{\mathrm{N}} \mathrm{A}-100-\mathrm{F}^{\mathrm{A}} & 120 \\
1.28 \overline{\mathrm{N}} \mathrm{A}-200-\mathrm{F}^{\mathrm{A}} & >600 \\
1.28 \overline{\mathrm{N}} \mathrm{A}-600-\mathrm{F}^{\mathrm{A}} & >600 \\
1.28 \overline{\mathrm{N}} \mathrm{A}-1200-\mathrm{F}^{\mathrm{A}} & >600
\end{array}
$$

\section{$>600$}

$>600$

$>600$

$>600$

90

144

265

$>600$

$$
\begin{aligned}
& 1.28 \mathrm{~N}^{\mathrm{A}}-0 \\
& 1.28 \overline{\mathrm{N}} \mathrm{A}-100-\mathrm{F}^{\mathrm{A}} \\
& 1.28 \overline{\mathrm{N}}^{\mathrm{A}}-600-\mathrm{F}^{\mathrm{A}} \\
& 1.28 \overline{\mathrm{N}} \mathrm{A}-1200-\mathrm{F}^{\mathrm{A}}
\end{aligned}
$$
$>600$
128
104
$>300$

\section{Solution E plus \\ $0.1 \mathrm{M}$ zirconium}

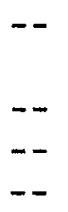

6.3

7.5

$--$

$-$

10.5

The soluble silica analysis obtained by the molybdate colorimetric method is also presented in Table A-3. Other workers in this laboratory[9] found that although waterglass diluted with distilled water could be measured accurately by the molybdate colorimetric method, silica concentrations of greater than 30 or $40 \mathrm{mg}$ per liter could not be measured when it was added to a 1.5M aluminum nitrate-1.5M nitric acid solution. A similar situation is reflected in these data. 
IDO- 14468

Page 26

The maximum tolecable gelatin dosage was $600 \mathrm{mg}$ of gelatin per liter for solution $F$. It appeared that colloidal silica (CAB-O-SIL) was a contaminant which reacted with gelatin.

Solution $\mathrm{H}$ also has a maximum tolerable dosage of $600 \mathrm{mg}$ of gelatin per liter. Zirconium analysis showed no removal of zirconium by gelatin treatment and filtration. It was concluded that the zirconium ion concentration must in some way affect the silicic contaminant already present in solution $E$ which originated from the dissolution of the fuel element.

From these and previous experiments it was concluded that due to the uncertainty of the composition of any waste solution, the prediction of a proper gelatin dosage would be exceedingly difficult, if not impossible, for a IBP process. One possibility foreseen is an additive in addition to gelatin which might conceivably prevent an overdosage and thus allow sufficient gelatin addition to take care of any existing surface active material. The Hexone data for solutions $\mathrm{B}$ and $\mathrm{C}$ in Table A-2 look far more promising so far as coalescence times are concerned.

\section{Flowsheet Study of a Grossly Contaminated Salvage Solution}

Solution I was a grossly contaminated solution similar to solution $B$. It was prepared from solutjon $E$ by adding 1000 ppm $\mathrm{SiO}_{2}$ as colloidal silica ( $\mathrm{CAB}-\mathrm{O}-\mathrm{SIL}$ ), $1000 \mathrm{ppm} \mathrm{SiO}_{2}$ as soluble silica (waterglass) and making the solution $0.1 \mathrm{M}$ in zirconium and $10-5 \mathrm{M}$ in DBP. Solution $I$ was tested at various gèlatin dosages using a $\overline{2} 10 \mathrm{C}$ coagulation period. Six hundred mg of the gelatin per liter was found to be the optimum dosage as was the case for the similar B solution.

These experiments were designed to study various plant flowsheet possibilities for a grossly contaminated salvage solution. Previous data indicated that a Hexone process would be promising, but removal of the bulk of the solids by filtration was desirable for the packed columns in this process, at ICPP. Filtrates were boiled following the filtration to test for any detrimental effects of later processing steps. The effects of boiling the solution with gelatin in TBP flowsheets were studied briefly.

For these experiments, $5 \mu$ stainless steel filters with Teflon o-rings and the 5-20 inches of mercury vacuum combination were used. All experiments were run using solution $I$, or solution $\sim$ IN $^{B}$ which was obtained by neutralizing solution I to $\mathrm{pH} 2$ with ammonium hydroxide. In two experiments the gelatin was added to the acid solution, then immediately neutralized before the coagulation period. These two are coded with an ( $n$ ) following the gelatin dosage code number.

Considerable variation in filtration rates was found. Solution I was acid when it was boiled with gelatin in experiments $1.28 \mathrm{NA}^{\mathrm{A}}-600-\mathrm{BF}$ and $1.28 \mathrm{NA}-600-\mathrm{BF}$. As shown in figures A-7-B and A-8, these filtration rates were poor. However, when the acid 
FIGURE $A-7$

FILTRATION DATA FOR SALVAGE SOLUTIONS

TBP FLOWSHEET STUDY OF SOLUTION I WITH ACID COAGULATION

FILTER SIZE: $5 \mu$ (0.1 sq. in. area)

VACUUM: $5^{\prime \prime-20 " ~ O F ~} \mathrm{Hg}$ COMBINATION
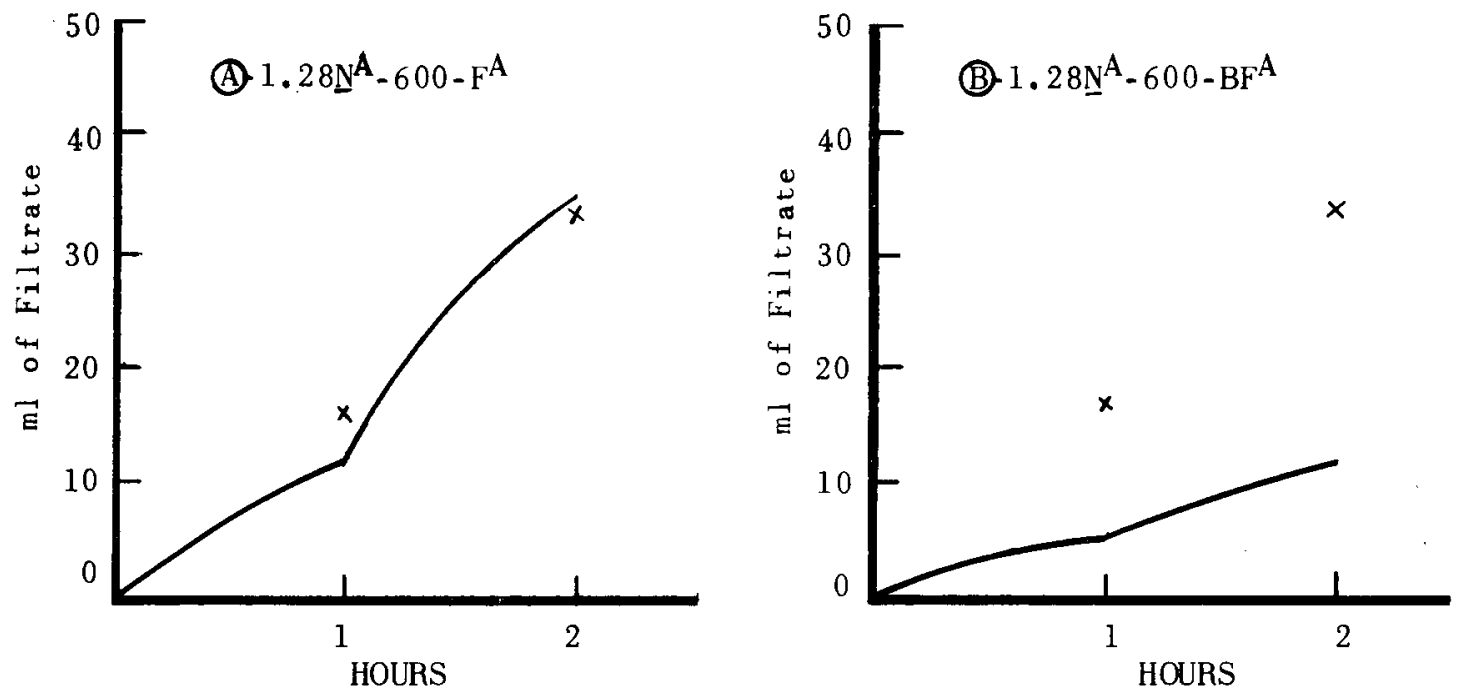

FIGURE A-8

FILTRATION DATA FOR SALVAGE SOLUTIONS

HEXONE FLOWSHEET STUDY OF SOLUTION I. WITH ACID COAGULATION

FILTER SIZE: $5 \mu$ (0.1 sq. in. area)

VACUUM: 5"-20" OF Hg. COMBINATION

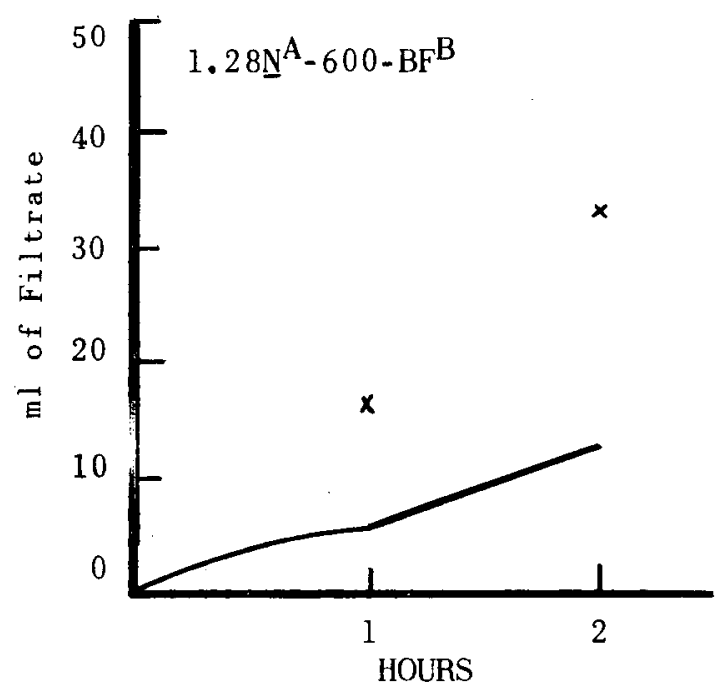


solution was not boiled during coagulation as in $1.28 \mathrm{~N}^{\mathrm{A}-600-F A}$ shown in Figure A-7-A, the filtration rate was approximately $16 \mathrm{ml}$ per hour as it had been in previous experiments.

Filtration rates for gelatin coagulation in an acid-deficient solution were in direct contrast to the acid coagulation. Experiment $\sim 1 N^{B}-600-F^{B}$ shown in Figure A-9-A had a poor filtration rate, but by boiling the acid-deficient solution as in experiments $\sim I N^{B}-600-B F B$ and $1.28 N^{A}-600(n)-B F^{B}$, good filtration rates were obtained as shown in Figure $A-9-B$ and $A-9-D$.

In experiment $1.28 \mathrm{~N}^{\mathrm{A}}-600(\mathrm{n})-\mathrm{FB}^{\mathrm{B}}$ shown in Figure $\mathrm{A}-9-\mathrm{C}$ one might expect a slow rate as in $\sim 1 N^{B}-600-F^{B}$, but this is not the case. The filtration rate is apparently controlled by the gelatin addition to the acid solution before the neutralization and is therefore the same as for 1.28NA-600-FA.

Table A-4 presents the data for the coalescence times in these experiments. Coalescence times were greater than 600 seconds in every case where gelatin was boiled with the acid solution whether it was before or after piltration. In $1.28 N^{A}-600(n)-B F^{B}$ where the solution and gelatin were combined while stili acid, then neutralized and boiled, some increase in coalescence time with Hexone occurred, but by reboiling the acid-deficient filtrate this acid-gelatin effect was partially counteracted. All other Hexone coalescence times were good.

In the hope that a lower gelatin dosage might work for grossly contaminated salvage solutions by boiling to coagulate, $200 \mathrm{mg}$ of gelatin per liter was added to the acid solution and boiled, then filtered. Both the filtration rate and the coalescence time with TBP were unacceptable.

TABIE $A-4$

COATESCENCE DATA FOR SAIVAGE SOLUTIONS

FLOWSHEET STUDY OF SOLUTION I

\begin{tabular}{|c|c|c|c|}
\hline & $\begin{array}{l}\text { Treatment } \\
\text { Code }\end{array}$ & $\begin{array}{c}\text { Coalescence Times } \\
\text { for Filtrates } \\
\text { (Seconds) }\end{array}$ & $\begin{array}{l}\text { Coalescence Time } \\
\text { For Boiled Filtrates } \\
\text { (Seconds) }\end{array}$ \\
\hline lowsheet & $\begin{array}{l}1.28 \mathrm{~N}^{A}-600-\mathrm{F}^{A} \\
1.28 \bar{N}^{A}-600-\mathrm{BF}^{\mathrm{A}}\end{array}$ & $\begin{array}{l}102 \\
>600\end{array}$ & $\begin{array}{l}>600 \\
>600\end{array}$ \\
\hline $\begin{array}{l}\text { xone } \\
\text { owsheet }\end{array}$ & $\begin{array}{l}1.28 N^{A}-600-B F^{B} \\
1.28 \bar{N} A-600(n)-F^{B *} \\
1.28 \bar{N} A-600(n)-B^{B} * \\
\sim 1 N^{B}-600-F^{B} \\
\sim 1 N^{B}-600-\mathrm{NF}^{B}\end{array}$ & $\begin{array}{r}600 \\
140 \\
246 \\
82 \\
166\end{array}$ & $\begin{array}{r}>600 \\
114 \\
180 \\
80 \\
140\end{array}$ \\
\hline
\end{tabular}

* $(\mathrm{n})$ denotes neutralization to $\mathrm{pH} 2$ immediately following the addition of the gelatin to the acid solution, but preceding the coagulation period. 


\section{FIGURE $\quad A-9$}

FILTRATION DATA FOF SALVAGE SOLUTIONS

\section{HEXONE FLOWSHEET STUDY OF SOLUTION I WITH ACID DEFICIENT COAGULATION}

FILTER SIZE: $5 \mu(0.1 \mathrm{sq}$. in. area)

VACUUM: $5^{\prime \prime}-2 \mathrm{O}^{n}$ OF $\mathrm{Hg}$ COMBINATION
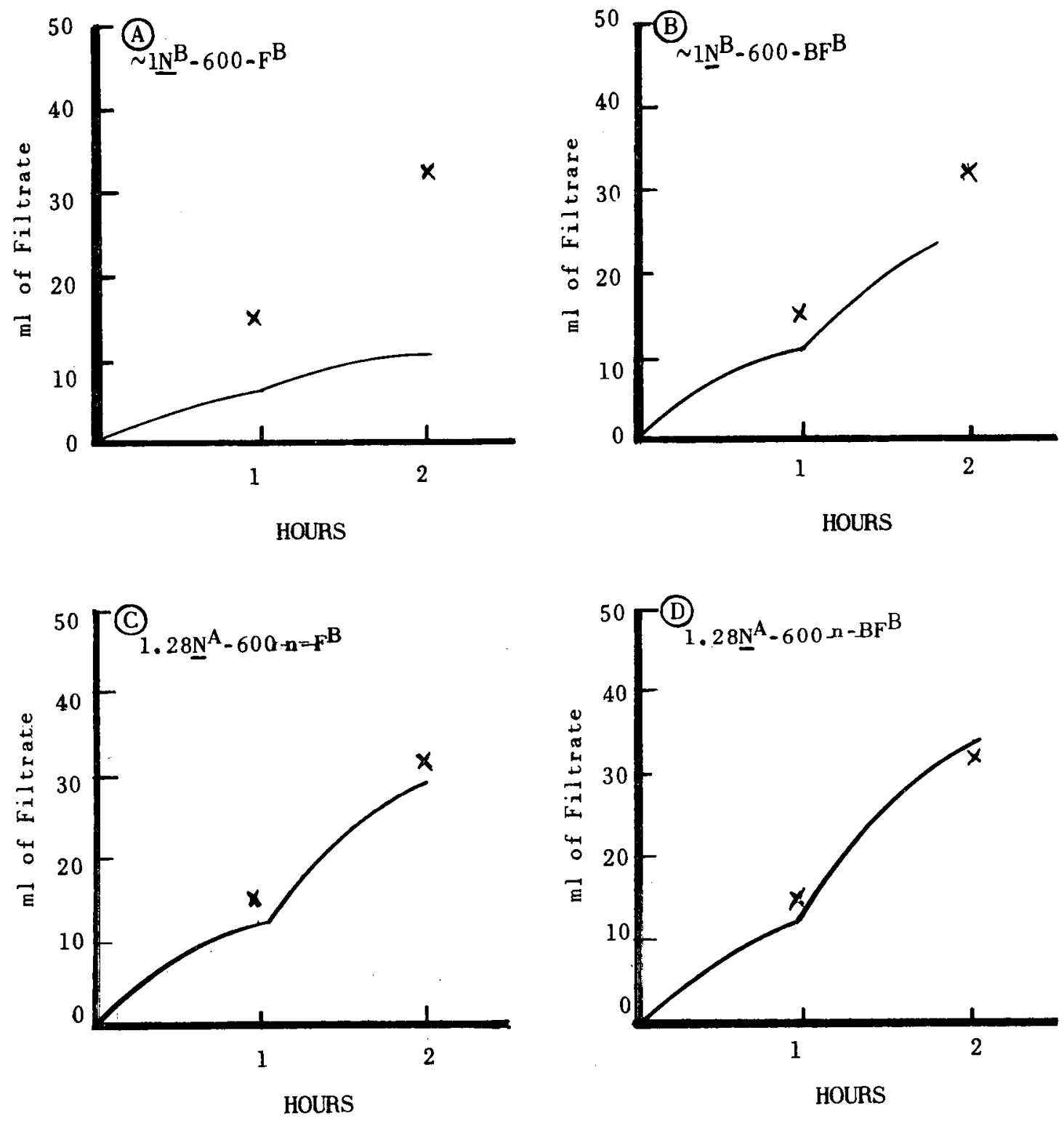
In conclusion a IBBP flowsheet is probably not feastble for salvage solutions since coalescence times were unacceptable when gelatintreated solutions were boiled either before or after filtration.

The most promising flowsheet was to boil the gelatin with an acid-deficient salvage solution and use a Hexone first cycle extraction. The problem of selecting an optimum dosage for a salvage solution of unknown composition would require further investigation for this flowsheet. No further work is planned unless there is a specific need for a Hexone flowsheet.

\section{B. Gelatin Treatment of Fuel Solutions}

The fuel solutions of interest were feeds from the dissolution of the high silicon-containing areas of aluminum-uranium fuel elements. A stock solution was prepared by batch dissolution of nonirradiated fuel segments. This $0.5 \mathrm{~N}$ - solution was $1.3 \mathrm{M}$ in aluminum nitrate, $0.5 \mathrm{~N}$ in nitric acid, contained about 1.2 grams pèr liter total silicon (estimated), and $17 \mathrm{ppm}$ soluble silica (measured by the molybdate colorimetric method). A small amount of uranium and 0.12 grams per liter zirconium were added. A $0.23 \mathrm{~N}^{\mathrm{B}}$ solution was prepared by adding ammonium hydroxide to the $0.5 \mathrm{~N}^{\mathrm{A}}$ solution.

Based on data obtained in Section A, most of the experiments were made with the 5-20 inches of mercury vacuum combination and $5 \mu$ filters.

1. Hexone Flowsheet Study

These experiments were performed to select the optimum flowsheet conditions for a gelatin treatment in connection with a proposal to process. silicon-rich fuel by a headend feed clarification and a Hexone first cycle extraction. For ease of plant operation it was desirable to adjust the solution to $0.23 \mathrm{NB}$ before the filtration step in a headend treatment.

One flowsheet considered was the addition of gelatin to the acid solution, coagulation, neutralization, and then filtration. The other flowsheet considered was neutralization of the solution, addition of the gelatin, coagulation, and then filtration. Samples were coagulated at either 21 or $98^{\circ} \mathrm{C}$.

These experiments were made using $5 \mu$ stainless steel filters with Teflon 0-rings and the 5-20 inches of mercury vacuum combination. Coalescence data and filtration rate evaluation are given in Table B-I. Note that coalescence times with Hexone were excellent even with no treatment whatsoever. A decrease in coalescence time would not have been discernible, but certainly gelatin did not interfere.

Solids removal was of interest for the packed columns in the Hexone plant and so filtration rates were of particular interest. As shown in Figure $B-I$ and the filtration rate evaluation in Table $B-I$, the rates were definitely improved by the gelatin treatment. Boiling during the coagulation period also appeared to increase filtration rates. 
FIGURE B-1

FILTRATION DATA FOR FUEL SOLUTIONS

1D0- 14468

PAGE 31

HEXONE FLOWSHEET STUDY
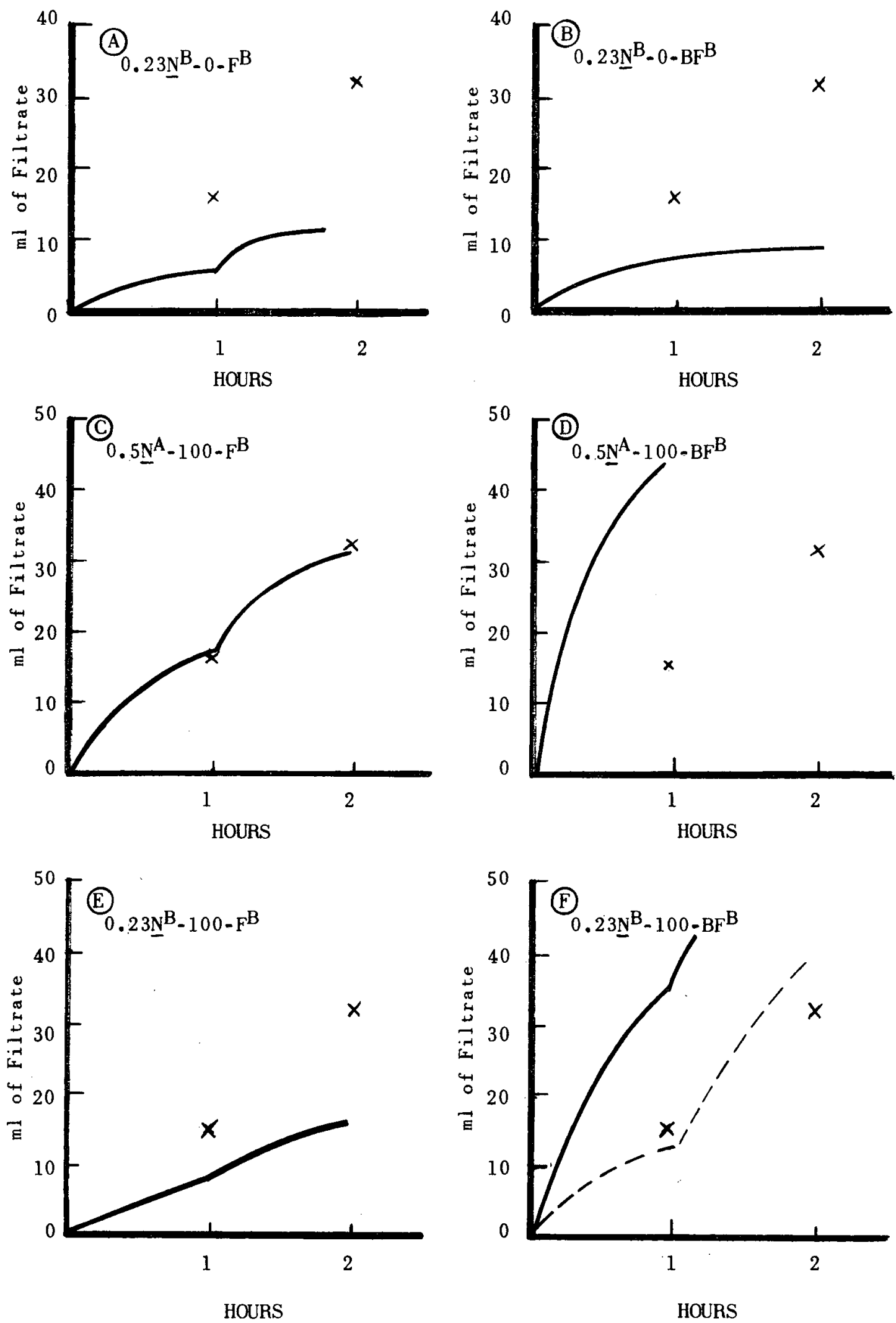
TABLE B-1

COALESCENCE DATA FOR FUEL SOLUTIONS

HEXONE FLOWSHEET STUDY

Treatment Code

\section{$0.23 \mathrm{~N}^{\mathrm{B}}$ Solution}

$0.23 \bar{N}^{B}$ Solution Boiled

$0.23 \mathrm{~N}^{\mathrm{B}}-\mathrm{O}-\mathrm{F}^{\mathrm{B}}$

$0.23 \underline{N}^{B}-0-B F^{B}$

$0.5 N^{A}-100-F^{B}$

$0.5 \bar{N}^{A}-100-B^{B}$

$0.2 \overline{3} \mathrm{~N}^{\mathrm{B}}-100-\mathrm{F}^{\mathrm{B}}$

$0.23 \bar{N}^{B}-200-B F B$

$0.23 \bar{N}^{\mathrm{B}}-200-\mathrm{BF}^{\mathrm{B}}$ (Rerun).
Filtration Rate Evaluation

None

None

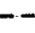

$--$

$+$

$-$

$++$

$+$
Coalescence Time with Hexone (Seconds)

\section{Effect of Acidity on Gelatin Coagulation}

The effect of acidity upon gelatin coagulation was studied by adjusting the acidity of the fuel solution with either nitric acid or ammonium hydroxide, adding gelatin, and boiling to coagulate. Data were obtained using $5 \mu$ stainless steel filters and the 5-20 inches of mercury vacuum combination.

Table B-2 presents the coalescence times and filtration rate evaluations for these experiments. Coalescence times were again found to be good with Hexone irrespective of the gelatin dosage or acidity during coagulation. Filtration rate curves for coagulation with $100 \mathrm{mg}$ of gelatin per liter are shown in Figure B-I for a $0.23 \mathrm{~N}^{\mathrm{B}}$ and a $0.5 \mathrm{~N}^{\mathrm{A}}$ solution and in Figure B-2 for a $0.1 N^{A}$ solution. Filtration curves for $200 \mathrm{mg}$ of gelatin per liter at various acidities are also shown in Figure $B-2$. The best filtration rates were obtained in the 0.1 and $0.5 \mathrm{~N}^{\mathrm{A}}$ solutions. In filtration rates, there appeared to be a relationship between acidity and over-dosage, especially in the $0.23 N^{B}$ solution. It was observed that upon boiling acid-deficient solutions containing gelatin, a stringy substance formed which adhered tenaciously to the glassware. For this reason and the fact that low filtration rates were obtained at high gelatin dosages, it was concluded that the gelatin treatment should be performed while the solution was still acid.

The acid filtration experiment presented in Table B-2 for comparison indicates that the acidity of the solution at the time of filtration had no effect so long as the sample was coagulated thoroughly in an acid solution by boiling. 
FIGURE $\quad \mathrm{B}-2$
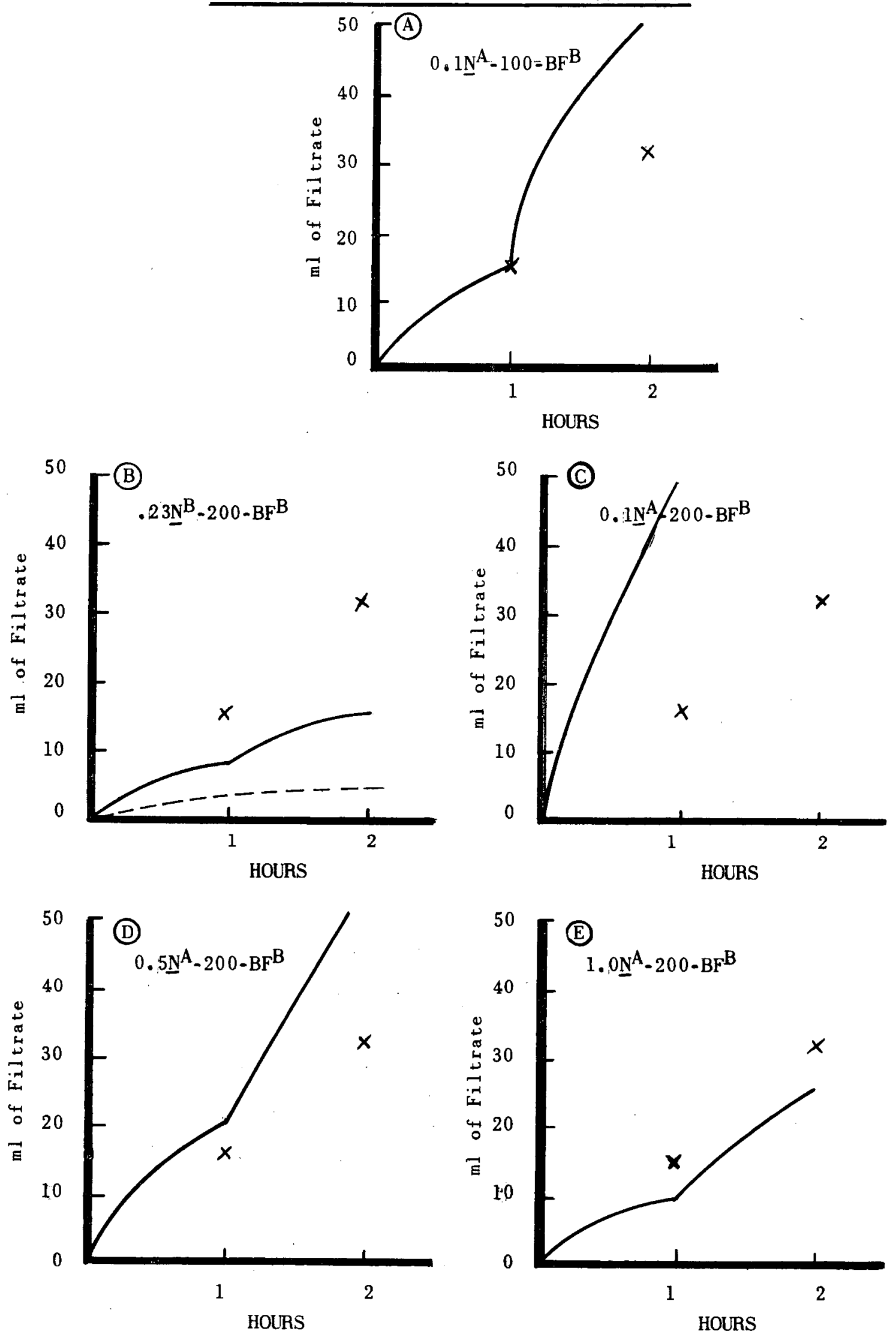
IDO- 14468

Page 34

TABLE B-2

COALESCENCE DATA FOR FUEL SOLUTIONS

EFFECT OF ACIDITY ON GELATIN COAGULATION

Treatment Code

$0.23 N^{\mathrm{B}}-100-\mathrm{BF}^{\mathrm{B}}$

$0.23 \overline{\mathrm{N}}^{\mathrm{B}}-100-\mathrm{BF}^{\mathrm{B}}$ (Rerun)

$0.1 \mathrm{~N}^{\mathrm{A}}-100-\mathrm{BFB}$

$0.5 \overline{\mathrm{N}} \mathrm{A}-100-\mathrm{BFB}$

$0.23 \mathrm{~N}^{\mathrm{B}}-200-\mathrm{BF}^{\mathrm{B}}$

$0.23 \bar{N}^{\mathrm{B}}-200-\mathrm{BF}^{\mathrm{B}}$ (Rerun)

$0.1 N A-200-B F B$

$0.5 \bar{N} A-200-B F B$

I. $O \bar{N} A-200-B F^{B}$

$0.5 N^{A}-100-B F^{A}$
Filtration Rate Evaluation

$++$

$+$

$+$

$++$

$\begin{array}{rr}- & 52 \\ - & -\end{array}$

$++$

$+$

$-$

$++$
Corlescence Time with Hexone (Seconds)

\section{TBP Flowsheet Study}

The purpose of these experiments was to evaluate the feed clarification of fuel solutions for a TBP process. Data were obtained with $5 \mu$ stainless steel filters and the 5-20 inches of mercury vacuum combination. Filtration rates are shown in Figure B-3 and coalescence data presented in Table B-3. It can be seen that gelatin treatment improved the filtration rates. These data also show that coalescence times were improved either by filtering without a gelatin treatment or by gelatin treatment without a filtration. Later experiments reported in Section C-l give further information regarding the effect of filtering without a gelatin treatment.

\section{TABLE B-3}

COALESCENCE DATA FOR FUEL SOLUTIONS

\section{TBP FLOWSHEET STUDY}

\begin{tabular}{|c|c|c|}
\hline Treatment Code & $\begin{array}{l}\text { Filtration Rate } \\
\text { Evaluation }\end{array}$ & $\begin{array}{l}\text { Coalescence Time with } \\
\text { TBP (Seconds) }\end{array}$ \\
\hline $0.5 \mathrm{NA}$ Solution & None & $>600$ \\
\hline $0.5 \overline{\mathrm{N}}^{A}$ Solution Boiled & None & $>600$ \\
\hline $0.5 \bar{N} \mathrm{~A}-0-F^{A}$ & - & 83 \\
\hline $0.5 \bar{N}^{A}-0-B F^{A}$ & -- & - \\
\hline $0.5 \overline{\mathrm{N}}^{\mathrm{A}}-100-\mathrm{BF}^{\mathrm{A}}$ & $+t$ & 75 \\
\hline 1. $O \overline{\mathrm{ON}} \mathrm{A}-100-\mathrm{BF}^{\mathrm{A}} \mathrm{A}$ & + & 107 \\
\hline $0.5 \overline{\mathrm{N}} \mathrm{A}-100-\mathrm{B}$ (not filtered) & None & $150^{*}$ \\
\hline
\end{tabular}


FIGURE B-3

FILTRATION DATA FOR FUEL SOLUTIONS

TBP FLOWSHEET STUDY
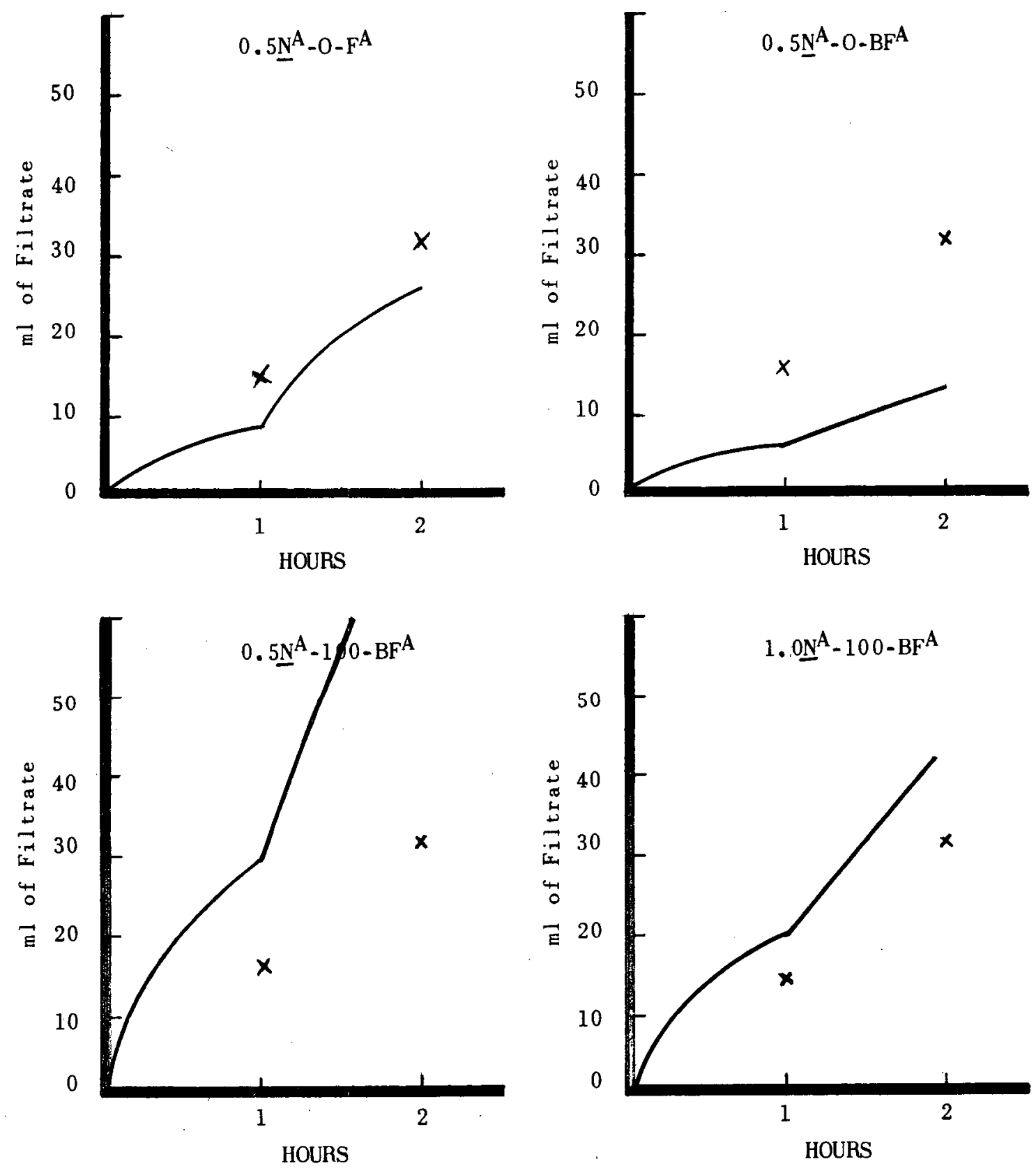
IDO- -14468

Page 36

\section{Effect of Temperature on Gelatin Coagulation}

From a process standpoint, it was desirable to avoid, if possible, the solution volume loss which would occur while boiling to coagulate with gelatin. The following experiments were performed to establish the limits of temperature and/or time necessary for coagulation for a gelatin treatment.

These data were obtained with 0.11 square inch area sintered glass filters of 4 or $8 \mu$ porosity. Due to the slower rates obtained, 5 inches of mercury vacuum was applied for only 30 minutes, then increased to 20 inches for the remainder of the filtration. The glass filters were calibrated with water at 5 inches of mercury vacuum and those selected which had fairly uniform rates of about $1 \mathrm{ml}$ per minute.

a. Coagulation Temperature. For this experiment, the gelatin-treated solutions were placed in controlled temperature baths for 30 minutes, then rapidly cooled in a cold water bath. Total coagulation time before filtration was one hour. Figure B-4 shows the rates obtained when the $0.5 \mathrm{NA}$ solution with $100 \mathrm{mg}$ of gelatin per liter was coagulated at $21,40,7 \overline{0}$, and $980^{\circ}$. The rate of filtration was directly proportional to the coagulation temperature. Coalescence times with TBP were all about one minute.

b. Coagulation Time at Constant Temperature. To determine if this was a kinetic effect, a series of samples was heated at $40{ }^{\circ} \mathrm{C}$ for 2 hours, I hour, and 30 minutes. Samples were placed in the temperature bath successively and then removed, cooled, and filtered simultaneously. Figure B-5 shows that increased time of digestion at $40^{\circ} \mathrm{C}$ did not improve the filtration rate. This indicated that the temperature effect was not an increase in the rate of reaction between the gelatin and the $0.5 \mathbb{N}^{\mathrm{A}}$ solution, but was a physical effect upon the gelatin[5].

The filtration rate for Figure B-5-A is lower than for

Figure B-4-B although both were coagulated for 30 minutes at approximately $40^{\circ} \mathrm{C}$. Variables known to have existed while running the curve for

Figure B-5-B are: the 1 per cent gelatin solutions had set for $1-1 / 2$ hours longer and was partially gelled, the sample was not coagulated an additional 30 minutes at room temperature, and the exact bath temperature was 2 to $3^{\circ} \mathrm{C}$ lower.

c. Effect of Pre-Gelled Gelatin. The following experiments were performed exactly as the ones in section B-4-a, except that a 1 per cent gelatin solution which was one week old and was completely gelied was used. Figure B-6 shows that the old gelatin retarded the filtration rate of the sample which was coagulated at $21^{\circ} \mathrm{C}$. However, at higher temperatures, the gelatin was "reactivated" and was as good or better than fresh gelatin. This confirmed the belief that the temperature effect was related to the physical state of the gelatin and that it would be necessary to coaguiate at $70^{\circ} \mathrm{C}$ or above. 
FIGURE B-4

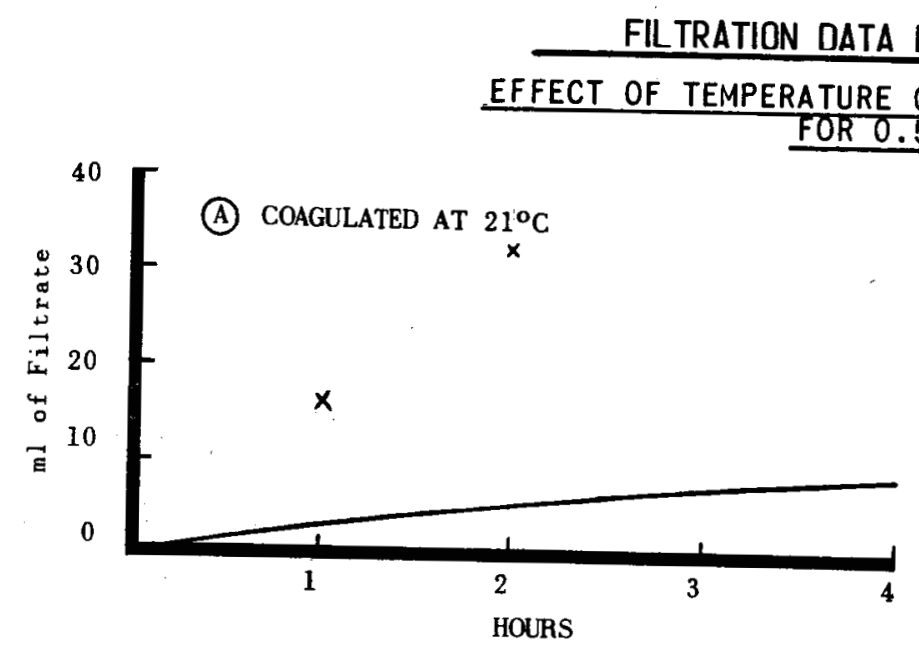

FUEL SOLIUTIONS
AELATIN COAGULATION
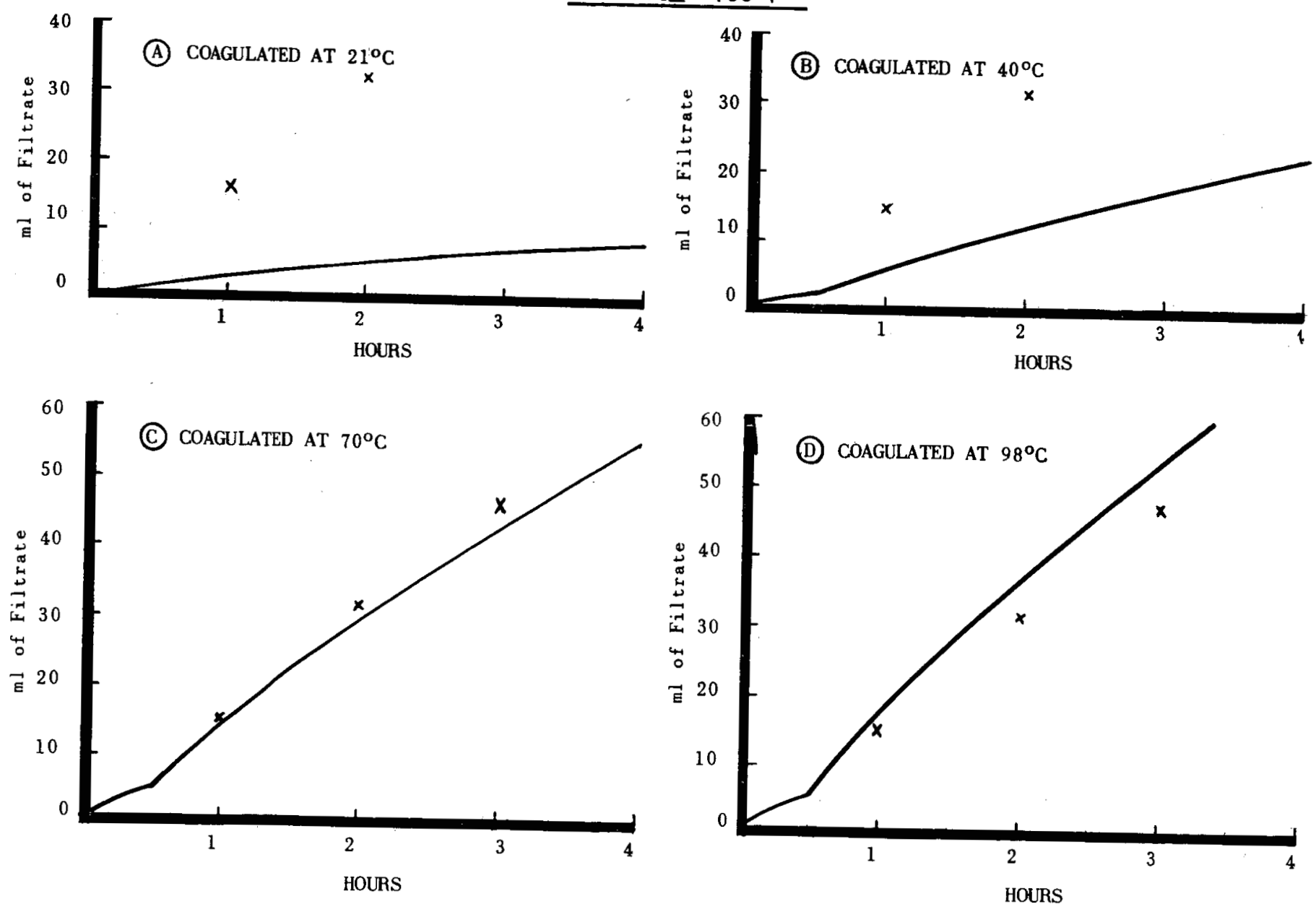
PAGE. 38

FIGURE B-5

FILTRATION DATA FOR FUEL SOLUTIONS
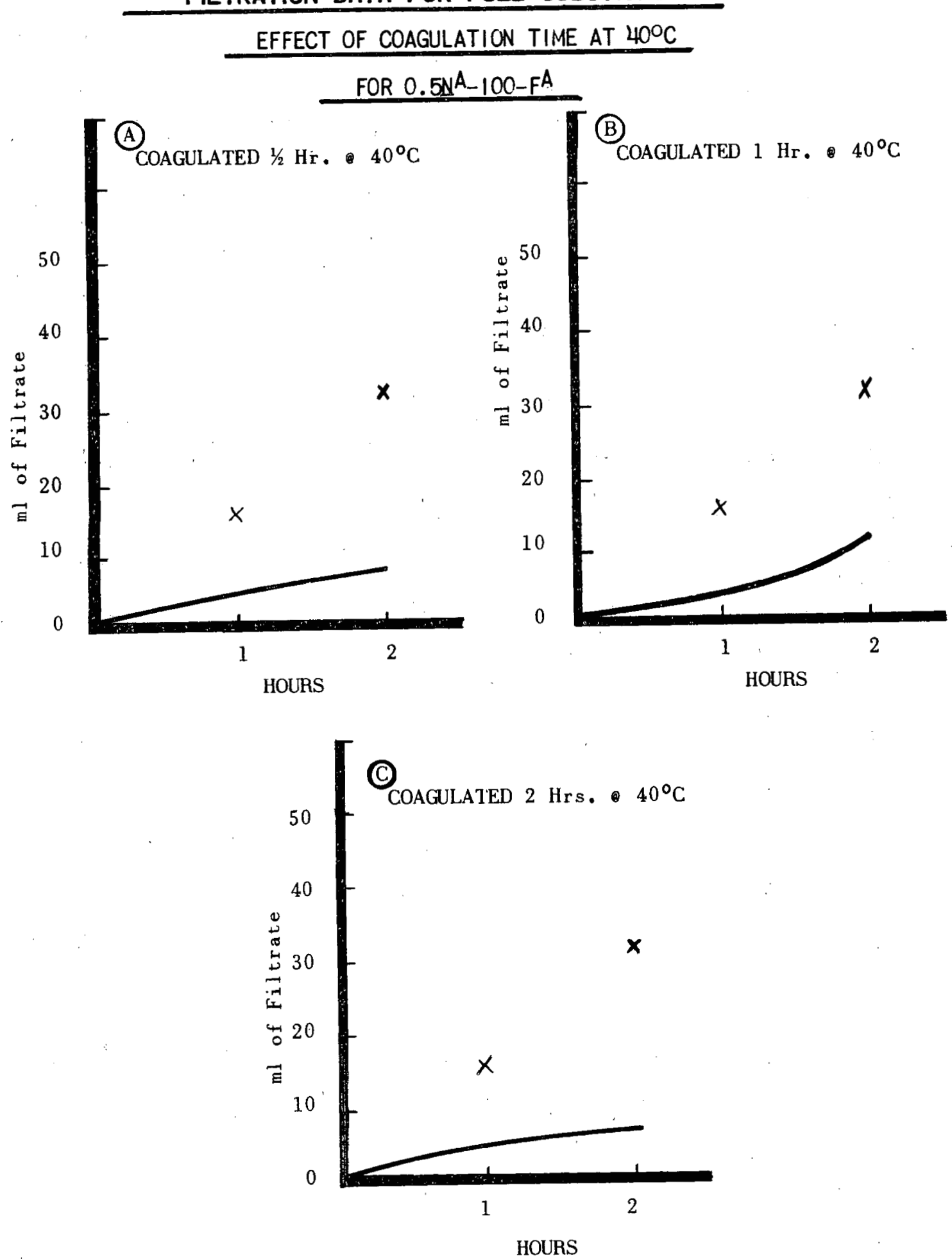
FIGURE $\quad 3-6$

\section{FILTRATION DATA FOR FUEL SOLUTIONS}

EFFECT OF USING PREGELLED GELATIN AT

VARIOUS COAGULATION TEMPERATURES

FOR $0.5 \mathrm{~N}^{\mathrm{A}}-100-\mathrm{F}^{\mathrm{A}}$
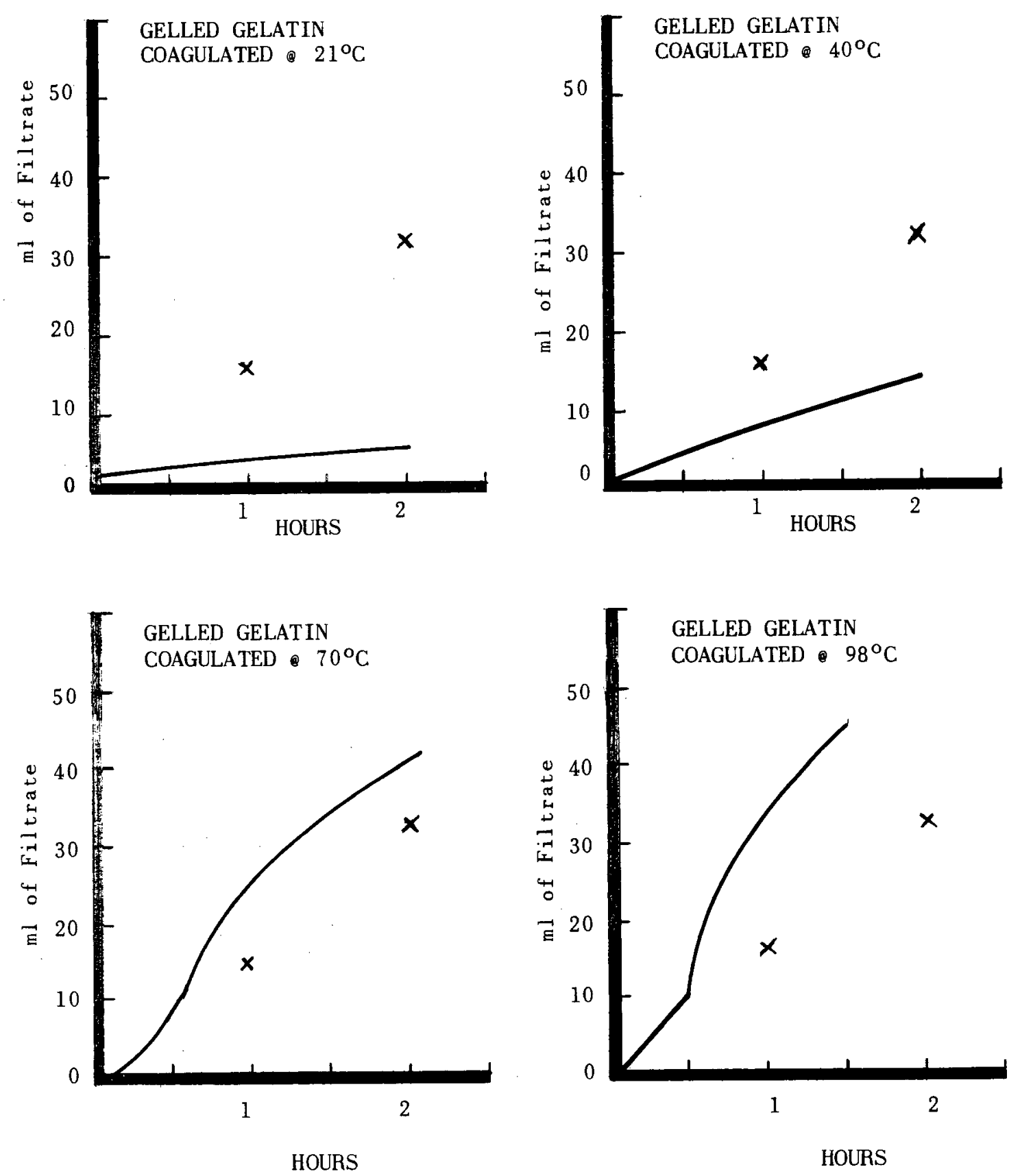

HOURS 
IDO- .14468

Page 40

\section{Filter Pore Size}

Although primary interest was in available 5 and $20 \mu$ porosity plant filters, a scoping study of other filter sizes was made. Stainless steel filters with Teflon 0-rings and the 5-20 inches of mercury vacuum combination were used for these experiments.

Filtration rates for the $0.5 \mathrm{NA}$ solution boiled with $100 \mathrm{mg}$ of gelatin per liter and filtered acid are show in Figure B-7. Data for acid-deficient filtrations are shown in Figure B-8. Data were obtained for duplicate runs using 5, 10, and $20 \mu$ filters. There was little difference in the filtration rates for the 5,10 and $20 \mu$ filters after the initial 15 minutes. Also, the rates appeared to be the same whether the solution was acidic or basic when filtered. The filtration rates for 35 and $65 \mu$ filters were extremely fast with estimated rates of 60 and $300 \mathrm{ml}$ per minute, respectively. There was a visible difference in the amount of solids which passed through the 20 and $35 \mu$ filters, and the amount of silicon found in the filtrate decreased sharply. If solids removal is desired, a filter of $20 \mu$ or less should be used.

Coalescence times for the acid-deficient filtrates with Hexone and for the acidic filtrates with TBP were all good. This agrees with data previously reported in Table B-I and B-3 which showed that gelatin treatment improved the coalescence time even without a filtration.

\section{Uranium Loss to Filter Cake}

The amount of uranium retained in the filter cake and the efficiency of washing the cake were studied for the gelatin headend treatment with $0.5 \mathrm{~N}^{\mathrm{A}}-100-\mathrm{BF}$ and $0.5 \mathrm{~N}^{\mathrm{A}}-100-\mathrm{BFB}$. Stainless steel filters with 1.0 square inch area (no 0 -rings) and $5 \mu$ porosity were used for this experiment. Vacuum was applied at 5 inches mercury throughout the filtration. In most cases, the treated solution was filtered to dryness and the cake air dried with suction for 10 to 15 minutes. For experiments described as wet filtrations, the crucibles were removed from the vacuum as soon as the liquid level crossed the cake. As can be seen in Table B-6, there was no difference between the so-called dry and wet filtrations.

In each experiment, duplicate filtrations of $50 \mathrm{ml}$ each were made, then one of the filter cakes was washed with $10 \mathrm{ml}$ of wash solution. Uranium in the cake was measured by X-ray fluorescence using precipitate from a uranium-free matrix for calibration. Results which are reported in Table B-4 give the weight of the precipitate, the X-ray fluorescence analysis of the filter cake, the total milligrams of uranium contained in the cake, and the per cent uranium lost based on the total uranilum filtered. There was no significant difference in cake size or uranium losses between acidic and acid-deficient filtrations. Uranium losses were about $2.5 \mathrm{mg}$ or 1.4 per cent for unwashed filter cakes. A water wash removed better: than 80 per cent of the uranium from the cake but unfortunately, it also washed better than half of the solids through the filter. When a salt solution which was $1.3 \mathrm{M}$ aluminum and $0.5 \mathrm{~N}$ nitric acid was 
FILTRATION DATA FOR FUEL SOLUTIONS

FILTER PORE SIZE FOR $0.5 \mathrm{~N}^{\mathrm{A}-100 \mathrm{BF}}$
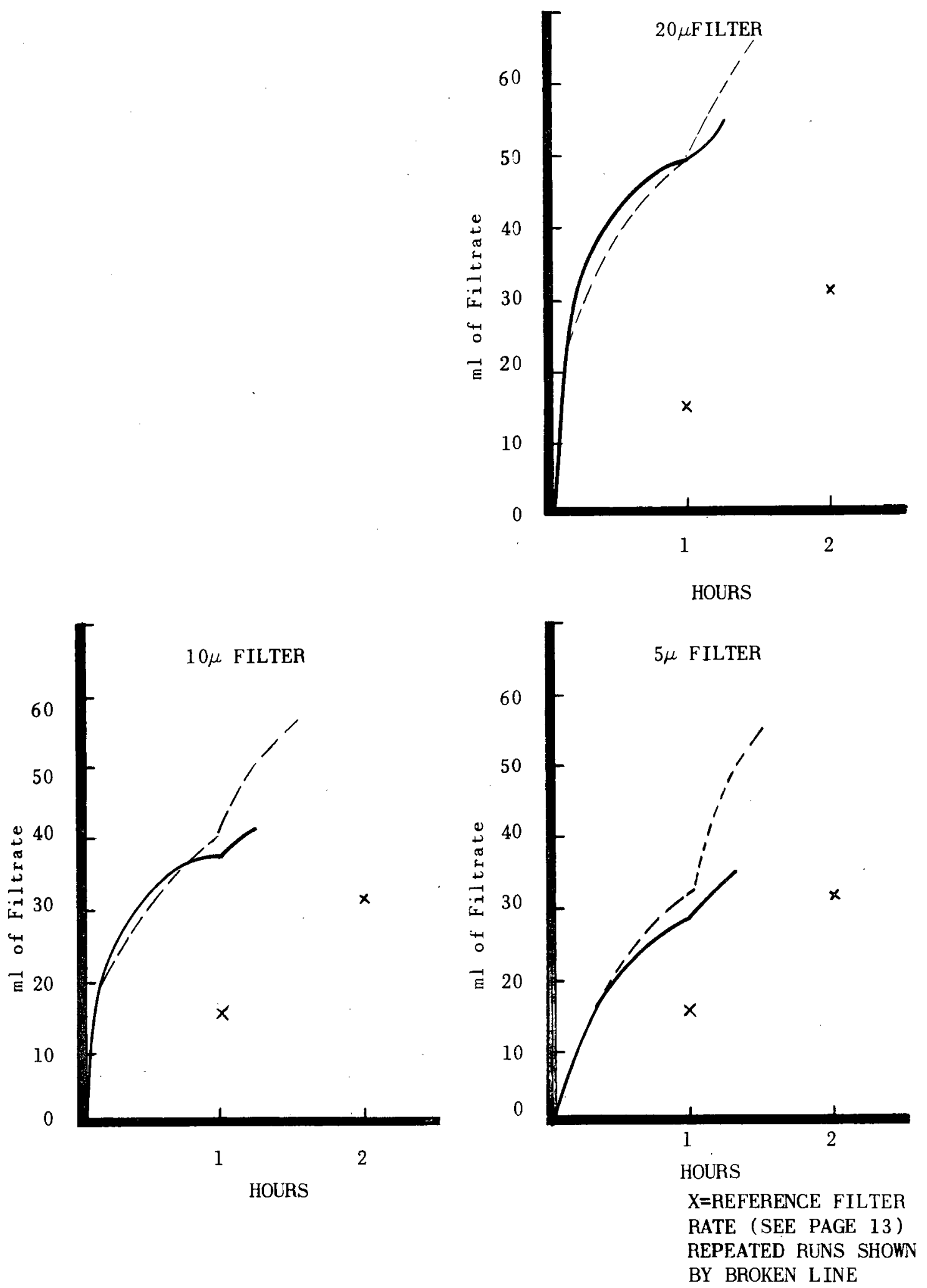
FIGURE B-8

FILTRATION DATA FOR FUEL SOLUTIONS

\section{FILTER PORE SIZE FOR $0.5 \mathrm{~N}^{\mathrm{A}}-100 \mathrm{BF}^{\mathrm{B}}$}

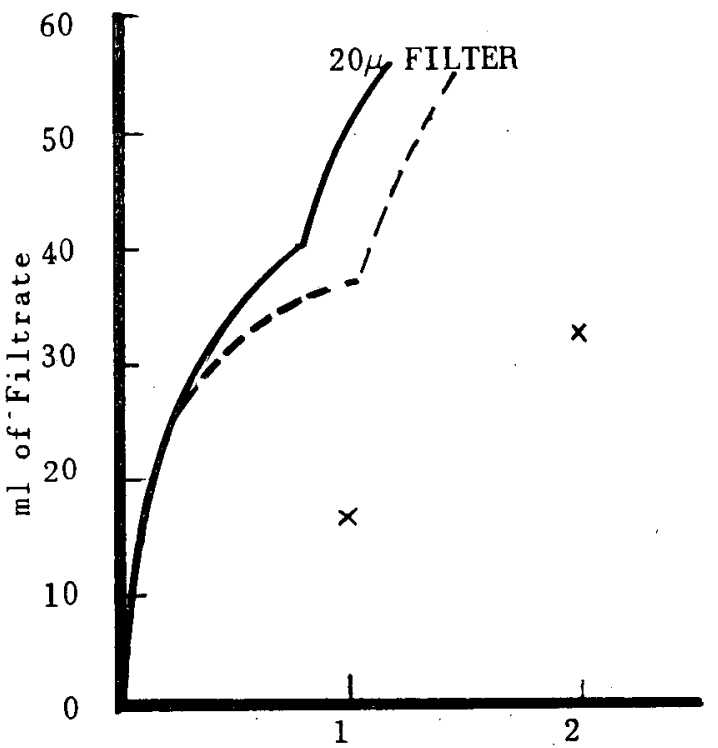

HOURS
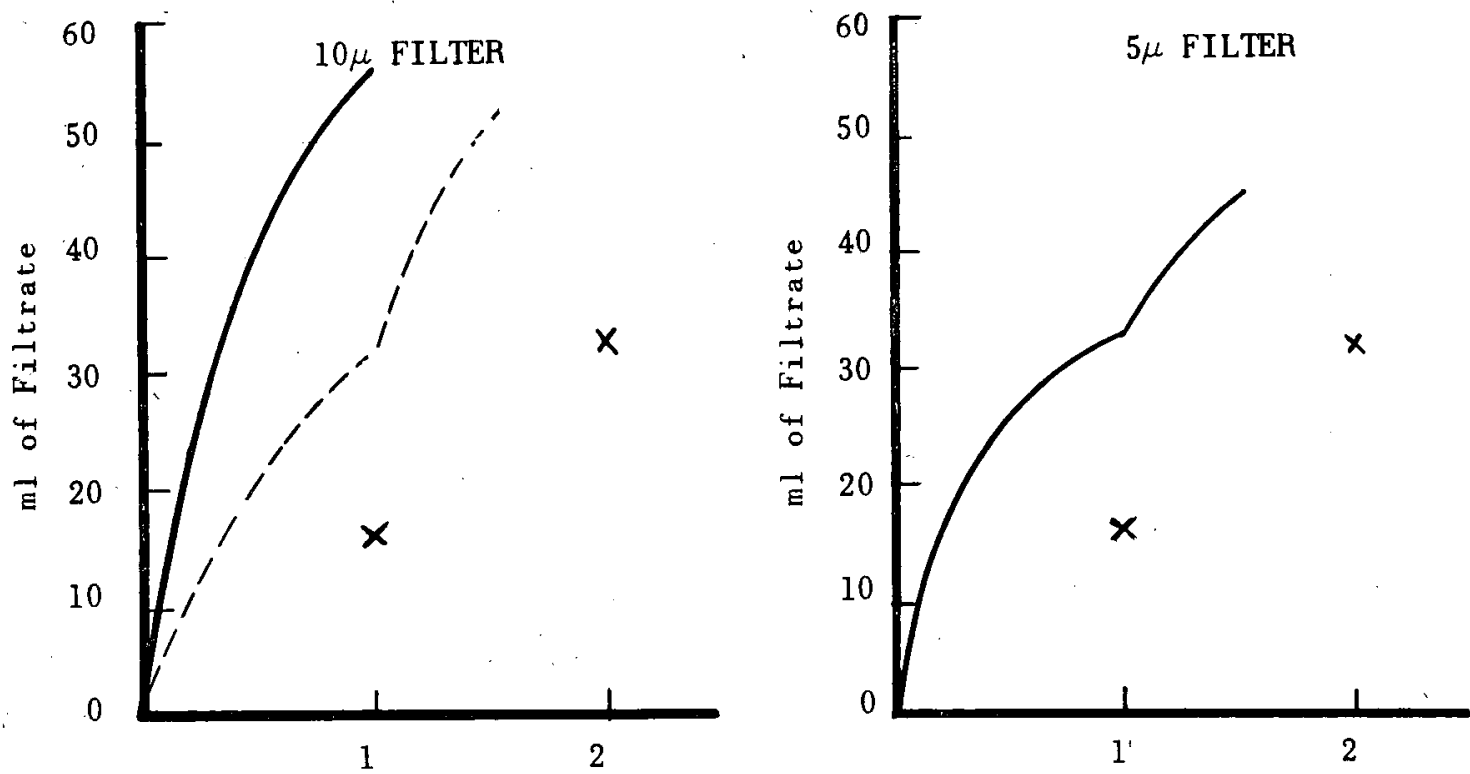

HOURS

HOURS

$X=$ =REFERENCE FILTER

RATE (SEE PAGE 13)

REPEATED RUNS SHOHN

BY BROKEN LINE 
TABLE B-4

\section{URANIUM LOSS DATA FOR FUEL SOLUTIONS}

\section{URANIUM RETEITION IN THE FILTER CAKE FROM A GETATIN HEADEID TREATMENT}

Precipitate from uranium-free matrix $=0.211$ grams

Uranium analysis of $0.5 \mathrm{~N}^{\mathrm{A}}$ solution was $3.67 \mathrm{mg} / \mathrm{ml}$ or $183 \mathrm{mg}$ in $50 \mathrm{ml}$

\begin{tabular}{|c|c|c|c|c|c|c|c|c|}
\hline \multirow[b]{2}{*}{ Treatment Code } & \multirow[b]{2}{*}{$\begin{array}{l}\text { Run } \\
\text { No. }\end{array}$} & \multirow[b]{2}{*}{$\begin{array}{l}\text { Filtration } \\
\text { Technique** }\end{array}$} & \multirow[b]{2}{*}{$\begin{array}{l}\text { Description } \\
\text { of } \\
\text { * Wash } \\
\end{array}$} & \multicolumn{4}{|c|}{ Filter Cake Data } & $\begin{array}{l}\text { Filtrate } \\
\text { Data } \\
\end{array}$ \\
\hline & & & & $\begin{array}{l}\text { ppt. Weight } \\
\text { from } \\
50 \text { mi of } \\
\text { Soln. (g) } \\
\end{array}$ & $\begin{array}{l}\% \text { Uranium } \\
\text { in ppt by } \\
\text { X-ray Fluor. }\end{array}$ & $\begin{array}{l}\text { Total U } \\
\text { in ppt. } \\
\text { (mg) }\end{array}$ & $\begin{array}{l}\% \text { Ioss of } \\
\text { U from } \\
50 \mathrm{ml} \\
\text { of Soln. }\end{array}$ & $\begin{array}{l}\text { Uranium in } \\
\text { Filtrate by } \\
\text { Colorimetric } \\
\text { Anal. (mg/ml) }\end{array}$ \\
\hline $0.5 \underline{N}^{A}-100-B F^{A}$ & $\begin{array}{l}1 \\
I \mathrm{~W}\end{array}$ & $\begin{array}{l}\text { Wet } \\
\text { Wet }\end{array}$ & $\begin{array}{l}\text { None } \\
\text { Water }\end{array}$ & $\begin{array}{l}0.221 \\
0.089\end{array}$ & $\begin{array}{l}1.3 \\
0.3\end{array}$ & $\begin{array}{l}2.77 \\
0.23\end{array}$ & $\begin{array}{l}1.5 \\
0.13\end{array}$ & $\begin{array}{l}3.57 \\
3.57\end{array}$ \\
\hline $0.5 \mathbb{N}^{\mathrm{A}}-100-\mathrm{BF}^{\mathrm{A}}$ & $\begin{array}{l}2 \\
2 W\end{array}$ & $\begin{array}{l}\text { Dry } \\
\text { Dry }\end{array}$ & $\begin{array}{l}\text { None } \\
\text { Water }\end{array}$ & $\begin{array}{l}0.213 \\
0.076\end{array}$ & $\begin{array}{l}1.2 \\
0.5\end{array}$ & $\begin{array}{l}2.65 \\
0.45\end{array}$ & $\begin{array}{l}1.4 \\
0.24\end{array}$ & $\begin{array}{l}3.54 \\
3.54\end{array}$ \\
\hline $0.5 \underline{N}^{\mathrm{A}}-100-\mathrm{BF}$ & $\begin{array}{l}3 \\
3 W\end{array}$ & $\begin{array}{l}\text { Dry } \\
\text { Dry }\end{array}$ & $\begin{array}{l}\text { None } \\
\text { Water }\end{array}$ & $\begin{array}{l}0.206^{*} \\
0.097^{*}\end{array}$ & $\begin{array}{l}1.2 \\
0.35\end{array}$ & $\begin{array}{l}2.44 \\
0.34\end{array}$ & $\begin{array}{l}1.4 * \\
0.19 *\end{array}$ & $\begin{array}{l}3.36 * \\
3.33 *\end{array}$ \\
\hline $0.5 N^{A}-100-B F A$ & $\begin{array}{l}4 \\
4 W\end{array}$ & $\begin{array}{l}\text { Dry } \\
\text { Dry }\end{array}$ & $\begin{array}{c}\text { None } \\
1.3 \mathrm{M} \mathrm{Al}\left(\mathrm{NO}_{3}\right)_{3} \\
\text { and } 0.5 \mathrm{~N} \mathrm{HNO}_{3}\end{array}$ & $\begin{array}{l}0.225 \\
0.193\end{array}$ & $\begin{array}{l}1.1 \\
0.26\end{array}$ & $\begin{array}{l}2.48 \\
0.50\end{array}$ & $\begin{array}{l}1.35 \\
0.27\end{array}$ & $\begin{array}{l}3.45 \\
3.54\end{array}$ \\
\hline
\end{tabular}

*The solution which was filtered had been diluted by neutralizing with ammonium hydroxide.

**Dry filter cakes were air dried with vacuum for 10 to 15 minutes. Wet filter cakes were removed immediately after completing the filtration. 
Page 44

used as the wash, the uranium loss was less than 0.3 per cent while only about 10 per cent of the solids was washed through the cake.

The filtrates analyzed by the colorimetric uranium method were in good agreement and indicated no gross uranium losses. Actual uranium losses cannot be calculated from this analysis because the small quantity of uranium lost was of the same magnitude as the precision of the method.

In conclusion, this bench-scale study indicated that uranium losses may be expected to be 0.2 to 0.3 per cent using one filter cake wash. It is recommended that an aluminum nitrate-nitric acid wash be used to insure the stability of the filter, cake.

\section{Removal of Solids from Filter Pores}

A few scoping studies were carried out in order to select a reagent suitable for cleaning plugged filter pores; having accomplished this, further studies were made to find the conditions under which this reagent would be the most effective. It was assumed that conditions leading to the most complete dissolution of the residue separated from gelatin-treated fuel solutions would be the most effective conditions for cleaning out filter pores.

The $0.5 N^{\mathrm{A}}$ fuel solution was made $100 \mathrm{mg}$ per liter in gelatin, boiled for $1 / 2$ hour under total reflux, allowed to cool to room temperature, and filtered. The residue was thoroughly dried with suction during filtration, and further dried by allowing it to stand at room temperature for several days. More effective drying procedures were not used for fear they would alter some of the characteristics of the solids.

In the preliminary studies approximately 0.2 gram of the solid was stirred with $10 \mathrm{ml}$ of $10 \mathrm{~N}$ nitric acid, $18 \mathrm{~N}$ sulfuric acid, and ION sodium hydroxide at $1000^{\circ}$ for $I / 2$ hour under total reflux. As shown in Table B-5, sodium hydroxide was the most effective of the three solutions. Further experiments involved stirring about.0.2.grams of residue for $1 / 2$ hour under total reflux at various temperatures with $10 \mathrm{ml}$ of various concentrations of sodium hydroxide. Two experiments were performed to indicate the solubility of the residue in 5 and $10 \mathrm{~N}$ sodium hydroxide under conditions of most effective dissolution. Tabie B-5 indicates that dissolving efficiency decreases slightly with decrease in sodium hydroxide concentration and more markedly with decrease in dissolution temperature. The solubility of the residue at $1000^{\circ}$ in both 5 and ION sodium hydroxide is about 80 grams per liter. 
TABIE B-5

RESIDUE SOLUBILITY DATA FOR FUEL SOLUTIONS

REMOVAT OF SOLIDS FROM FILTER PORES

Stirred 0.5 hour under total reflux

\begin{tabular}{|c|c|c|c|c|c|}
\hline \multirow[b]{2}{*}{$\begin{array}{c}\text { Dissolving } \\
\text { Reagent Used } \\
\end{array}$} & \multirow{2}{*}{$\begin{array}{c}\text { Volume of } \\
\text { Dissolving } \\
\text { Reagent, } \\
\text { ml } \\
\end{array}$} & \multirow{2}{*}{$\begin{array}{l}\text { Dissolution } \\
\text { Temperature, } \\
{ }^{\circ} \mathrm{C} \\
\end{array}$} & \multirow{2}{*}{$\begin{array}{c}\text { Initial } \\
\text { Weight of } \\
\text { Residue, } \\
\text { grams } \\
\end{array}$} & \multicolumn{2}{|c|}{ Weight of } \\
\hline & & & & Grams & $\begin{array}{c}\% \text { of Initial } \\
\text { Weight }\end{array}$ \\
\hline ION $\mathrm{HINO}_{3}$ & 10 & 100 & 0.2662 & 0.0988 & 37 \\
\hline $18 \overline{\mathrm{N}} \mathrm{H}_{2} \mathrm{SO}_{4}$ & 10 & 100 & 0.1805 & 0.0675 & 37 \\
\hline $10 \overline{\mathrm{N}} \mathrm{NaOH}$ & 10 & 100 & 0.1998 & 0.1953 & 98 \\
\hline $5 \overline{\mathrm{N}} \mathrm{NaOH}$ & 10 & 100 & 0.1970 & 0.1872 & 95 \\
\hline $1 . \overline{5} \mathrm{~N} \mathrm{NaOH}$ & 10 & 100 & 0.1998 & 0.1816 & 91 \\
\hline $5 \mathrm{~N}^{-} \mathrm{NaOH}$ & 10 & 60 & 0.2038 & 0.1719 & 84 \\
\hline $5 \overline{\bar{N}} \mathrm{NaOH}$ & 10 & 21 & 0.2098 & 0.1129 & 54 \\
\hline $1 \mathrm{ON} \mathrm{NaOH}$ & 10 & 60 & 0.2052 & 0.1984 & 97 \\
\hline $10 \overline{\mathrm{N}} \mathrm{NaOH}$ & 5 & 100 & 0.5566 & $0.4 \overline{453}$ & 80 \\
\hline $5 \overline{\mathrm{N}} \mathrm{NaOH}$ & 5 & 100 & 0.4036 & 0.3350 & 83 \\
\hline
\end{tabular}

8. Transfer of Solids from Filters

One hundred milligrams per liter of gelatin were added to each of 3 aliquots of $300 \mathrm{ml}$ of the $0.5 \mathrm{NA}$ fuel solutions, boiled for $1 / 2$ hour under total reflux, and cooled to room temperature. The residue from each aliquot was separated on separate $5 \mu$ sintered glass filters (filter area was 0.8 square inches). Cold water, water at $1000^{\circ}$, or $10 \mathrm{~N}$ sodium hydroxide at $1000 \mathrm{C}$ was immediately used to transfer the solids from the filter as a slurry. The slurry was removed from the filter by applying a vacuum to a tube extending into the slurry (kept in suspension by means of air sparging). Although the hot caustic solution was more effective in removing the solids from the filter than hot water, both reagents at $100^{\circ} \mathrm{C}$ gave adequate performance. The filters appeared to be unplugged after the solids were removed from filters using either hot water or hot caustic.

\section{Characterization of Surface Active Solids}

\section{Filtration Mechanism and Particle Size Estimation}

As has been shown in Table B-3, filtration without gelatin treatment improved coalescence times. Results from a filter pore size study are shown in Figure $\mathrm{C}-1$ for $0.5 \mathrm{~N}^{\mathrm{A}}-\mathrm{O}-\mathrm{F}^{\mathrm{A}}$ using stainless steel filters with O-rings and the 5-20 inches of mercury vacuum combination. Filter rates were again found to be independent of filter size after the first 15 minutes of filtration. Filtration rates for the 5 and $10 \mu$ filters were not as good as for the gelatin-treated solutions. 
PAGE 46

FIGURE $\quad \mathrm{C}-1$

FILTRATION DATA FOR CHARACTERIZATION OF

SURFACE ACTIVE SOLIDS

FILTER PORE SIZE FOR $0.5 \mathrm{~N}^{\mathrm{A}-0-F^{A}}$
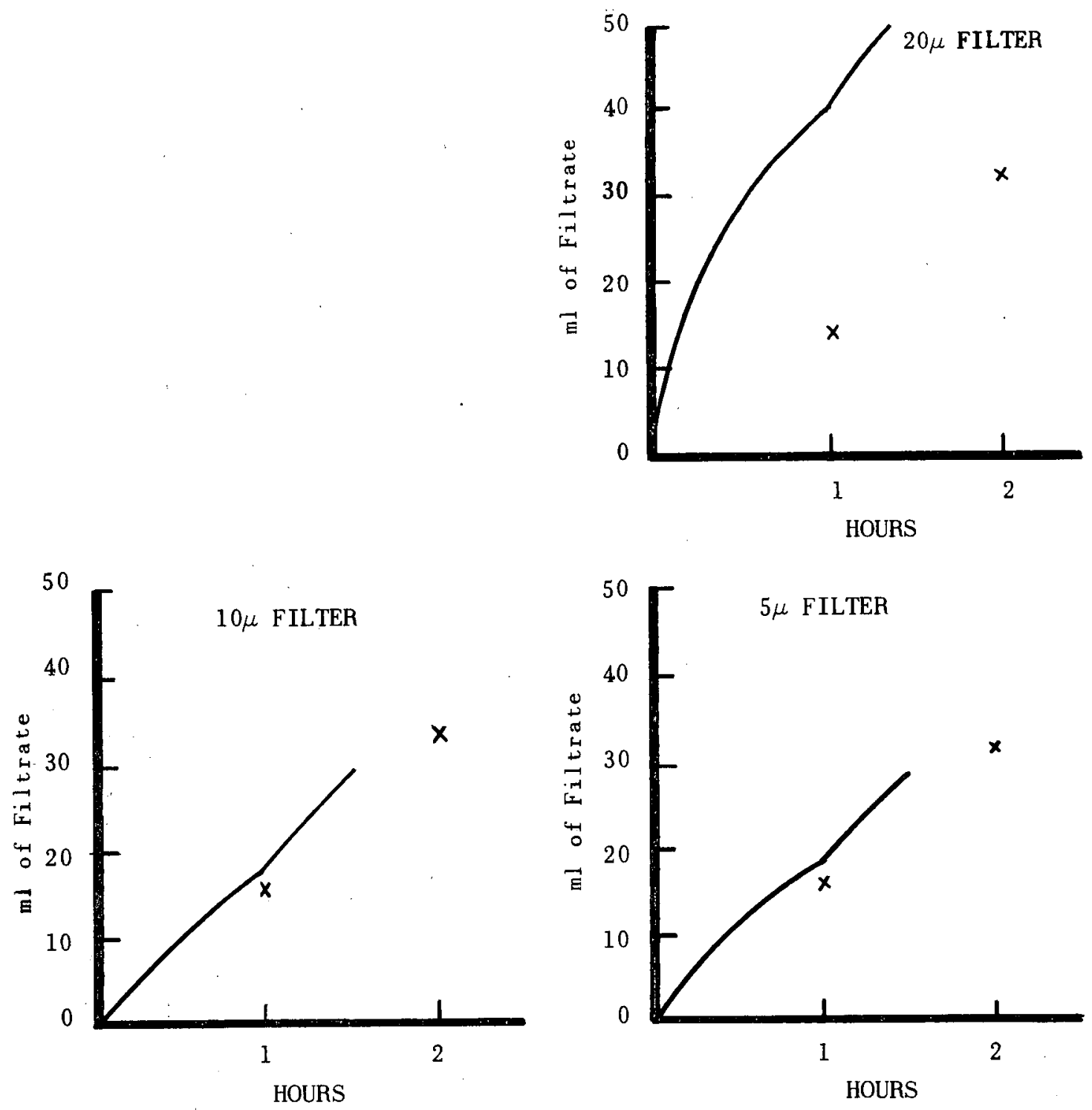
Coalescence times as well as aluminum and silicon analyses for these filtrations are given in Table $\mathrm{C}-\mathrm{l}$. The filtrates were dried, heated to $1000{ }^{\circ} \mathrm{C}$, and analyzed for aluminum and silicon by emission spacyescopy. The silicon-aluminum ratio and the coalescence time decreased simultaneously showing that the surface activity was due to some form of silicon.

\section{TABLE C-I}

\section{COAIESCENCE DATA FOR CHARACTERIZATION OF SURFACE ACTIVE SOLIDS}

Filter Pore Size for $0.5 \mathbb{N}^{\mathrm{A}}-0-\mathrm{FA}^{\mathrm{A}}$ (No Gelatin Treatment)

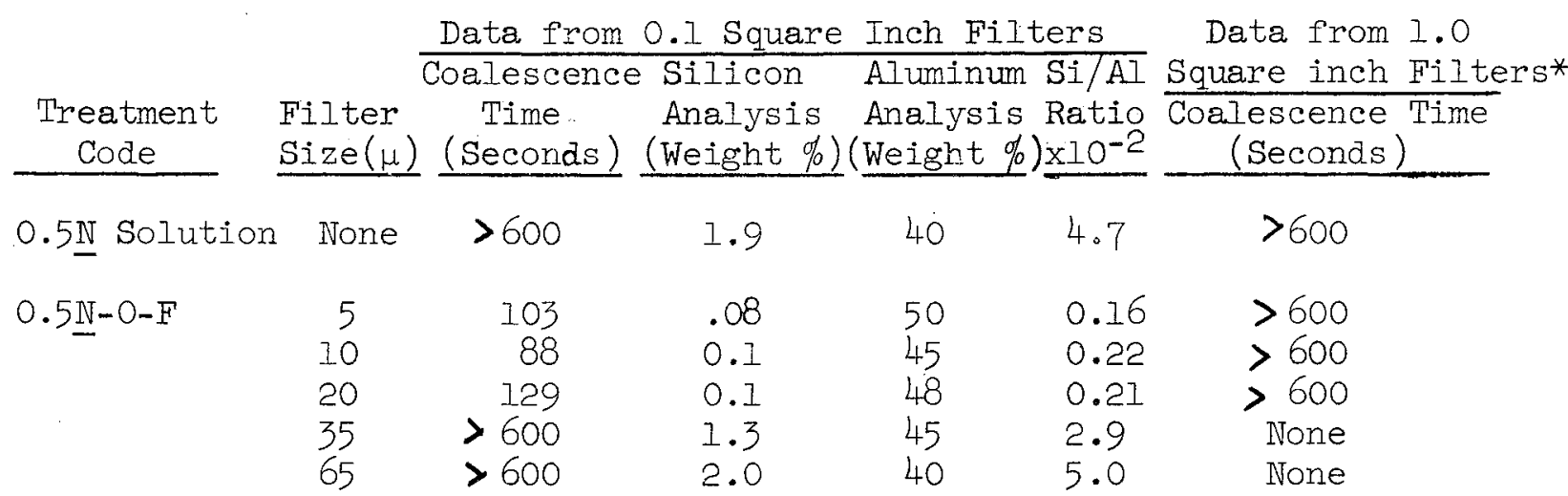

*Data obtained from the first $15 \mathrm{ml}$ of the filtrate collected.

The data shown in the last column of Table C-I were obtained by collecting the first $15 \mathrm{ml}$ of the filtrate which came through the new one square inch stainless steel filter (no O-rings). From these data and the filter pore size studies reported in Section B-5, it was concluded that solids removal was not a function of filter size, but rather of the filter cake formation. Once formed, the filter cake becomes the filtering media which removes the surface active solids. The $15 \mathrm{ml}$ of solution containing solids which passed through the one square inch filter did not produce sufficient cake to act as a filter media.

The surface activity was shown to be due to solids because it was decreased in these solutions by filtration. Based on the filtration data, it was concluded that most of these particles were less than $35 \mu$ in apparent diameter, but a sufficient number were greater than $20 \mu$ to form a cake on a $20 \mu$ filter. Particles of less than $5 \mu$ in apparent diameter were surface active since coalescence times were not decreased by the $5 \mu$ filter with a one square inch area.

\section{Possible Identity of Surface Active Solids}

a. Partition of Solids in the Fuel Solution. In an effort to characterize the surface active solids, $200 \mathrm{ml}$ of the $0.5 \mathrm{NA}$ solution was allowed to stand for several days. Gray crystalline silïcon settled to the bottom. The supernate which had a strong Tyndall beam was decanted. 
The settled solids were combined with $200 \mathrm{ml}$ of aluminum nitrate-nitric acid solution of the same concentration as the original solution. The following observations were made:

(1) The supernate had a ITB coalescence time of greater than 600 seconds while the TBP coalescence time of the settled solids in the aluminum nitrate-nitric acid solution was 77 seconds. This showed that the surface active material remained in the supernate and was not due to the crystalline silicon.

(2) The stability of the supernate indicated that it was a colloidal suspension. The individual small particles in the supernate were examined at 970 magnifications with an optical microscope and estimated to be less than 0.1 micron in apparent diameter. These particles were found singly and in pairs, but mostly as small clusters. Figure C-2 is a microphotograph of these particles at about 7000 total. magnifications.

(3) When the supernate was coagulated with $100 \mathrm{mg}$ of gelatin per liter at the boil, the TBP coalescence time decreased to 167 seconds. Figure $\mathrm{C}-3$ shows the coagulation of the small solids by the gelatin at about 7000 total magnifications. The shadow effect seen in the photograph appeared to be translucent gelatin by visual examination.

(4) The solution containing the settled solids was boiled with total reflux for 3 hours at acidities of $0.5 \mathrm{~N}^{\mathrm{A}}, 1.5 \mathrm{NA}$, and $0.23 \mathrm{~N}^{\mathrm{B}}$. TBP coalescence times obtained were 92,90 , and $1 \overline{0} 5$ seconds, respectively. After the $0.5 \mathrm{~N}^{\mathrm{A}}$ solution stood for one week at $21^{\circ} \mathrm{C}$, the coalescence time was still 87 seconds. This showed that the surface activity could not be readily produced from the crystalline silicon.

$$
\text { b. The Consideration of Silica vs. Silicon. Based on the }
$$
preceding experiment, filtration data, and work reported in IDO-14441 [1] it was concluded that the surface active material in feed from siliconrich aluminum-uranium fuel was an amorphous colloidal particle with high silicon content. It was either present in the fuel due to the metallurgical history of the element or produced during dissolution or feed adjustment steps. Since there was no analytical method available to distinguish between silicon and silica, the exact composition of the particle was not known. Experimental facts which substantiate one theory or the other are presented here for consideration.

Iler[3] as well as Lewis, et al., [4] have described the formation of colloidal silica by the dehydration and polymerization of silicic acid. Okura[10] found that silica molybdate colorimetric method. measures the silica which is in the ionic state but not the coiloidal or polymerized silica. Based on other work at this laboratory[9] it was concluded that such a polymerization of silica will take place when the silicate ion is added to an aluminum nitrate-nitric acid media. The gelatin coagulation of polymerized silica (colloidal) has also been described by Iler [3]. It was proposed that there is a hydrogen bond between the nitrogen of the gelatin and the hydrogen of the SiOH groups. on the polysilicic acid. If we assume that the silicic colloid is silica, 


\section{FIGURE C-2}

MICROPHOTOGRAPH OF FUEL SOLUTION SUPERNATE

BEFORE GELATIN TREATMENT ( 7000X)
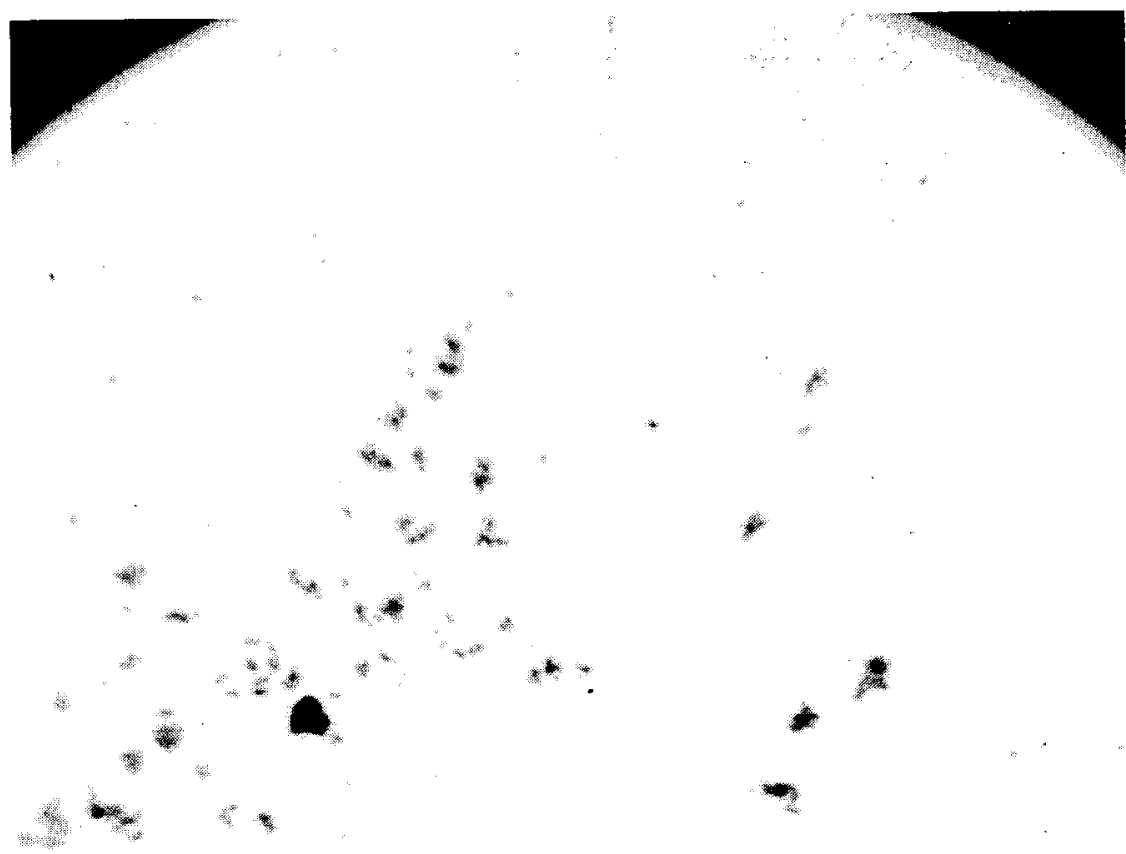
FIGURE C-3

MICROPHOTOGRAPH OF FUEL SOLUTION SUPERNATE

AF"TER GETATIN TREATMENT ( 7000X)

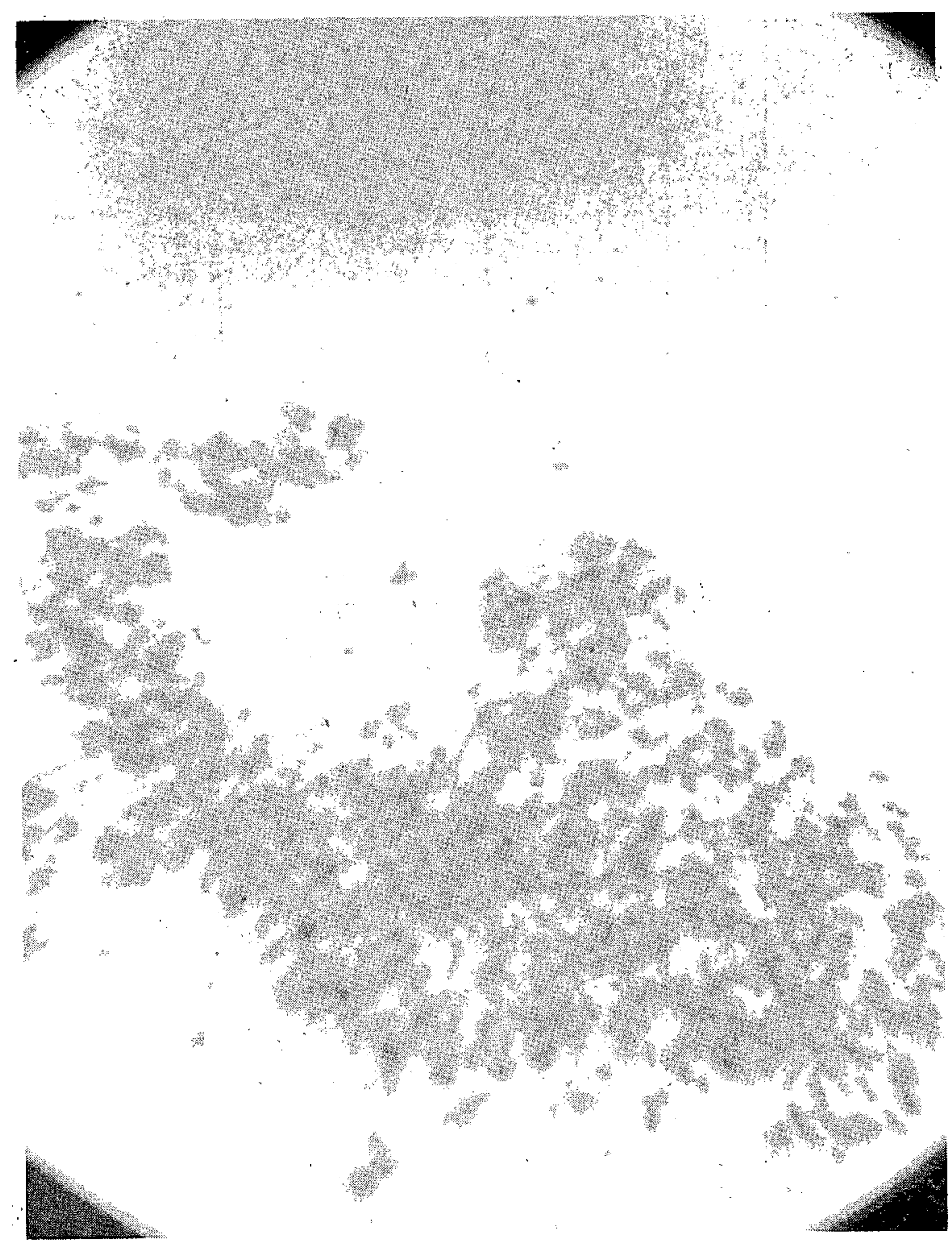


we have a ready explanation of the gelatin treatment.

This silica theory was substantiated by the fact that when colloidal silica was added as CAB-O-SII to fuel solutions, the gelatin demand was increased. It was also shown that an increase in zirconium ion required a higher gelatin dosage although zirconium was not removed by the filtration. One possible explanation is that in the presence of the zirconium ion there is more colloidal silica formed due to an increased degree of polymerization of the silicic acid. Another possibility is that the zirconium ion charges the kind or amount of charge on the colloidal particles. In any case, the absence of zirconium ion was undoubtedly a major. factor in the low surface activity obtained by Parrett and Rolidell] in similar fuel solutions.

There were certain experimental facts which were not in complete agreement with the theory of the gelatin coagulation of silica. It was observed that coagulating for 2 hours at $40^{\circ} \mathrm{C}$ did not have the same effect upon the filtration rates as coagulating for 30 minutes at the boiling point. This experiment indicated that the coagulation was not entirely due to a reaction between the gelatin and silica, but it was also due to the gelation of gelatin which is dependent on solution properties such as temperature and acidity[5]. Also, in the uranium loss study, it was found that the filter cake was unstable when washed with water. This may have indicated that the gelatin was not held by a strong chemical bond; however, the 30 per cent of solids which remained in the calse may have been chemically bonded while only the excess gelatin was removed.

To accept the silica theory, it is necessary to justify the presence of silica in these fuel solutions, either as soluble silica or colloidal silica. It was reported in DP-293[2] that silicon will dissolve slowly in nitric acid. Neither the fine amorphous solids or solution surface activity was produced by boiling the crystalline silicon for two hours at $7.5 \mathrm{M}$ acid in our laboratory, but this was a less severe treatment than reported in DP-293. There is the possibility that silica was present as an impurity in the silicon-aluminum alloys. However, from the thermodynamic properties of the oxides one would expect most of the silica to be converted to silicon with the formation of alumina.

The presence of "amorphous" silicon as well as crystalline silicon in the fuel elements has been described as a function of metallurgical history[1]. There are many references to amorphous silicon[II], but none have been found. which describe it as a colloidal suspension. Coagulation of silicon particles would probably occur by occlusion of the particles during the gelation of the gelatin.

\section{OONOLUSIONS}

A gelatin headend treatment including filtration was studied for two types of silicon-containing solutions: plant salvage solutions which are composites of jetted column interfaces and high uranium raffinates and feed from the dissolution of silicon-rich aluminum-uranium fuels. 
Gelatin treatment of synthetic salvage solutions improved the coalescence times but had no effect upon the filtration rates. However, the selection of a proper gelatin dosage for good coalescence times was exceedingly difficult for solutions of unknown composition. It was found that synthetic salvage solutions, even with 1000 ppm soluble silica added as sodium silicate, required only $100 \mathrm{mg}$ of gelatin per liter while the addition of 9 grams per liter zirconium ion or 1000 ppm colloidal silica as CAB-0-SII increased the gelatin demand to $600 \mathrm{mg}$ per liter. A TBP flowsheet with acid feed was not suitable for salvage solutions because bolling the gelatin-treated solution, either before or after filtration, gave unacceptable coalescence times. The optimum flowsheet for a grossly contaminated salvage solution using $600 \mathrm{mg}$ of gelatin per liter was to coagulate a IN acid-deficient solution by boiling and to use a Hexone first cycle extraction.

Conditions were established for a gelatin headend treatment and filtration of feed solutions from aluminum-uranium fuels containing as high as 4 per cent silicon by weight. For optimum gelatin treatment of these solutions, $100 \mathrm{mg}$ per liter of gelatin was added as a 1 per cent aqueous solution to a 0.1 to $0.5 \mathrm{~N}$ acid solution and coagulated at the boiling point for 30 minutes. If solids removal is desired, a $20 \mu$ filter or smaller should be used with a filter cake buildup period at reduced vacuum. The filtration rate was approximately the same for 5 and $20 \mu$ filters after the initial filter cake was formed.

The selection of a process flowsheet for fuel solutions will depend on the results desired. In the Hexone flowsheet studies, Hexone coalescence times were good with a $0.23 \mathrm{~N}^{\mathrm{B}}$ solution without any treatment, but when solutions were properly coagulated in an acid solutions, filtration rates were greatly improved. No difference in filtration rates was observed between acidic and acid-deficient filtrations. In TBP flowsheet studies, the TBP coalescence times which were extremely poor without gelatin treatment were good after proper gelatin coagulation. Coalescence times were also improved by filtration without gelatin treatment so long as a good filter cake was formed. However, a proper gelatin treatment increased the filtration rate.

Uranium loss to the filter cake with no filter cake wash was about 1.5 per cent of the total uranium filtered. This was decreased to $0.2-0.3$ per cent with either a water or an aluminum nitrate-nitric acid waish. The salt wash is recommended to prevent the dissolution of the gelatin and the washing of solids through the filter. Filter cakes can be adequately transferred with boiling water. Should filter pores become plugged, the solids can be dissolved with ION sodium hydroxide at $600 \mathrm{C}$.

The surface active materials present in the silicon-containing fuel solutions were characterized. Crystalline silicon solids, estimated to be mostly 20 to $35 \mu$ in apparent diameter, were found not to be surface active. The amorphous particles which were found to be surface activity were about $0 . I \mu$ in apparent diameter or less and remained in colloidal suspension. 
Based on the experimental results obtained in this study, it was concluded that these surface active solids most probably were colloidal. hydrated silica particles; however, the possibility that finely divided "amorphous" silicon was the surfactant was not completely disproved. 
1. Parrett, $0 . W$. and $K$. I. Rohde, The Effect of Silicon in the Reprocessing of a Uranium Aluminum Alloy, IDO-14441, May 10; 1958.

2. Groh, H. J., Removal of Silica from Solutions of Nuclear Fuels, DP-293, June $\overline{1958 .}$

3. Iler, R. K., The Colloid Chemistry of Silica and Silicates, Cornell University Press, New York, 1955.

4. Lewis, W. K., L. Squires, and G. Broughton, Industrial Chemistry of Colloidal and Amorphous Materials, p. 183-186, MacMillan, New York, 1942 :

5. Ibid. p. 223-234.

6. Hill, O. F。, Classified Report, HW-26104. (1952).

7. Parrett, O.W., and K. L. Rohde, (To be published).

8. Burger, L. I., I. M. Rehn, and C. M. Slansky, Physical Properties and Distribution Coefficients of the System: Uranyl Nitrate Aluminum Nitrate - Nitric Acid - Water - Hexone. Part V. pH Values, HW-14559, September 29, 1949.

9. Rhodes, D. W., Private Communication to Slansky, C. M., Phillips Petroleum Co.' AED, Idaho Falls, Idaho, Rhod-13-58A-N, December 10, i1958.

10. Takeshi Okura, Colorimetric Determination of Silica, J. Chem. Soc. Japan, Pure Chem. Section, 72 p. 927-930, 1951; CA 46, 6995.

11. Mellor, J.W., A Comprehensive Treatise of Inorganic and Theoretical Chemistry, Vol.6, p. 145-160, Longmans, Green and Co., London, 1947. 